\title{
"I want to be like you!" The influence of role models on entrepreneurial intention
}

\author{
KATHARINA FELLNHOFER, Lappeenranta University of Technology, Finland \\ SUSAN MUELLER, University St. Gallen
}

Dr. Katharina Fellnhofer

Lappeenranta University of Technology

LUT School of Business and Management

P.O. Box 20

53851 Lappeenranta

FINLAND

Phone +43 6644212920

Email: katharina.fellnhofer@lut.fi

Prof. Dr. Susan Mueller

Assistant Professor of Entrepreneurship

University of St. Gallen, Swiss Research Institute of Small Business and Entrepreneurship

Dufourstrasse 40a

9000 St. Gallen

SWITZERLAND

Phone +41712247124

Email: susan.mueller@unisg.ch

\section{Acknowledgment}

The author would like to thank the Austrian Science Fund FWF [J3740] and the Swiss National Science Foundation (SNSF) for supporting this research project.

The author would like to express appreciation to Prof. Kaisu Puumalainen for supervising the overall research project. Furthermore, the author would like to thank the following researchers for their assistance with the collection of the data: Prof. Helena Sjögrén, Prof. Nicos Komninos, Prof. Panagiotis Tsarchopoulos and Mag. Franz Stummer. Special thanks are extended to the entrepreneurs sharing their entrepreneurial lives with us. 
Accepted Author Manuscript: Electronic version of an article published as Journal of Enterprising Culture 2018 26:02, 113-153 [https://doi.org/10.1142/S021849581850005X] C) [copyright World Scientific Publishing Company] [https://www.worldscientific.com/doi/abs/10.1142/S021849581850005X]

"I Want to Be Like You!": The Influence of Role Models on Entrepreneurial Intention

Katharina Fellnhofer (LUT School of Business and Management, Lappeenranta University of Technology, P. O. Box 20, 53851 Lappeenranta, Finland) and

Susan Mueller (Swiss Research Institute of Small Business and Entrepreneurship University of St. Gallen, Dufourstrasse 40a, 9000 St. Gallen, Switzerland)

\section{“I want to be like you!”: The Influence of Role Models on Entrepreneurial In- tention}

Explaining individual's entrepreneurial intention is a central element in entrepreneurship research. The purpose of this paper is to illustrate that role models have an indirect effect on students' entrepreneurial intention. We draw on a sample of 266 individuals and apply structural equation modeling. Our results show that role models have a positive and significant influence on entrepreneurial intention via the antecedents described in the theory of planned behavior, the entrepreneurial event model, and the integrated version of these models. With our study, we aim to contribute to a more comprehensive understanding of the path through which role models influence entrepreneurial intention.

\section{Introduction}

In this study, we analyze how entrepreneurial role models influence entrepreneurial intention (EI). We define an entrepreneurial role model as "a cognitive construction based on the attributes of people in social roles an individual perceives to be similar to him or herself to some extent and desires to increase perceived similarity by emulating those attributes" (Gibson 2004, p. 136) and EI as the intention to found a company (e.g., Kolvereid 1996a; Krueger, Reilly, and Carsrud 2000; Tegtmeier 2006). Since we are interested in the path through which role models impact EI we include those attitudes and beliefs in our study that have been proven to be relevant antecedents for influencing EI. Namely, we tested how role models impact EI via the constructs included in the most prominent intention models, namely in Ajzen's (1991) theory of planned behavior (TPB) and Shapero and Sokol's entrepreneurial event model (EEM). Also, we tested the influence of role 
Accepted Author Manuscript: Electronic version of an article published as Journal of Enterprising Culture 2018 26:02, 113-153 [https://doi.org/10.1142/S021849581850005X] C) [copyright World Scientific Publishing Company] [https://www.worldscientific.com/doi/abs/10.1142/S021849581850005X]

"I Want to Be Like You!": The Influence of Role Models on Entrepreneurial Intention

Katharina Fellnhofer (LUT School of Business and Management, Lappeenranta University of Technology, P. O. Box 20, 53851 Lappeenranta, Finland) and

Susan Mueller (Swiss Research Institute of Small Business and Entrepreneurship University of St. Gallen, Dufourstrasse 40a, 9000 St. Gallen, Switzerland)

models on an integrated intention model combining the TPB and the EEM (Schlaegel, and Koenig 2013).

With regard to career choice intentions, multiple studies have shown that role models can positively influence the intention to become an entrepreneur (e.g., BarNir, Watson, and Hutchins 2011; Scherer, Adams, Carley, and Wiebe 1989; Rosique-Blasco et al., 2016). Intentions, in turn, play a considerable role in entrepreneurship research. They proved to be the best predictor of planned behavior, particularly when the behavior in question is "rare, hard to observe, or involves unpredictable time lags" (Krueger, Reilly, and Carsrud 2000, p. 411), characteristics that certainly apply to entrepreneurship. Also, meta-analytical studies showed that different kinds of intention models indeed provide a high explanatory power between intentions and behaviors (Kim, and Hunter 1993). Additionally, Kautonen et al. (2013) claim that the intention-behavior relationship holds regardless of age, gender, experience, education, and the nature of one's entrepreneurial ambition.

However, the path through which role models positively influence EI has not yet been explored in a comprehensive manner. For example, some studies treat role models as one element of subjective norms but not as a separate construct (e.g. Krueger, Reilly, and Carsrud 2000). Other studies look at the effect of role models on selected variables but omit others. For example, BarNir et al. (2011) analyze the direct effect of role model exposure on entrepreneurial career intention and the moderating and mediating influences of self-efficacy and gender. With that, they provide valuable and important insights for specific role model mechanisms. However, attitudes, perceived desirability and feasibility - constructs that have been identified as important antecedents of EI in 
Accepted Author Manuscript: Electronic version of an article published as Journal of Enterprising Culture 2018 26:02, 113-153 [https://doi.org/10.1142/S021849581850005X] C) [copyright World Scientific Publishing Company] [https://www.worldscientific.com/doi/abs/10.1142/S021849581850005X]

"I Want to Be Like You!": The Influence of Role Models on Entrepreneurial Intention

Katharina Fellnhofer (LUT School of Business and Management, Lappeenranta University of Technology, P. O. Box 20, 53851 Lappeenranta, Finland) and

Susan Mueller (Swiss Research Institute of Small Business and Entrepreneurship University of St. Gallen, Dufourstrasse 40a, 9000 St. Gallen, Switzerland)

previous research - were not included in the model. Thus, how role models influence EI can still be considered a black box.

A better understanding of the mechanisms through which role models influence EI is important for the following reason. Increasing entrepreneurial activity is on top of the agenda for policymakers since entrepreneurs and their small and medium sized companies (SMEs) constitute the backbone of many economies including the European Union's (EU) economies (Muller, Devnani, Julius, Gagliardi, and Marzocchi 2016). More precisely, SMEs create two-thirds of all jobs and generate more than $50 \%$ of total commercial value in the EU. Nine out of ten SMEs are microenterprises with fewer than ten employees (Eurostat 2017) in which entrepreneurs play a driving force. Next, encouraging EI is also important to address the problem of finding suitable company successors, which will affect thousands of companies in the next year. For example, it is estimated that 70,000 to 80,000 Swiss companies will need a successor until the year 2021 and that for half of those companies there will not be family member willing or ready to take over (Bird, Halter, Zellweger, Kissling Streuli, Andric, Christen, Gachet, and Schenk 2016). Referring to a global perspective, our findings could also contribute to facilitate entrepreneurship in developing countries. Recently, Williams, Martinez-Perez, \& Kedir (2017) highlight the impact of entrepreneurship in the informal sector that comprise a substantial characteristic of the developing world (approximately $40-60 \%$ of GDP) (Schneider, and Williams 2013). This informal economy employs $60 \%$ of the labor (Jütting, and de Laiglesia 2009) of which 70\% are entrepreneurs (ILO 2013). For encouraging EI to advance the entrepreneurship process globally, policy-makers, support organi- 
Accepted Author Manuscript: Electronic version of an article published as Journal of Enterprising Culture 2018 26:02, 113-153 [https://doi.org/10.1142/S021849581850005X] C) [copyright World Scientific Publishing Company] [https://www.worldscientific.com/doi/abs/10.1142/S021849581850005X]

"I Want to Be Like You!": The Influence of Role Models on Entrepreneurial Intention

Katharina Fellnhofer (LUT School of Business and Management, Lappeenranta University of Technology, P. O. Box 20, 53851 Lappeenranta, Finland) and

Susan Mueller (Swiss Research Institute of Small Business and Entrepreneurship University of St. Gallen, Dufourstrasse 40a, 9000 St. Gallen, Switzerland)

zations, and educators should exploit the impact of role models to a much larger degree. The engagement of existing entrepreneurs in the awareness-creation ecosystem (e.g., media, education) could support wide-spreading the idea of entrepreneurship as an alternative attractive career path. However, if we want to have a targeted influence on EI we need to be aware of the mechanisms through which role models actually influence EI.

To our knowledge, our study will therefore be the first empirical study analyzing the path of how role models influence students' EIs in a comprehensive manner that includes those antecedents that have been proven to be most relevant for shaping entrepreneurial career intentions. We aim to answer the following research question with our study:

\section{How do entrepreneurial role models affect entrepreneurial intention?}

We find that role models have indeed a positive and significant influence on EI through the antecedents described in the TPB, the EEM, and the integrated version of the two models. Interestingly, we did not find a direct impact of role models on EI. We recommend future researchers to conduct research on the impact of role models by employing the integrated model provided by Schlaegel and Koenig (2013) since it provides the most detailed insights into the mechanisms through which role models influence EI.

We organized this contribution as follows: Initially, we present two entrepreneurial intent models, namely the TPB (Ajzen 1991) and the EMM (Shapero, and Sokol 1982), plus an integrated version of the two theories provided by Schlaegel and Koenig (2013). First, we develop hypotheses to confirm the predictions suggested in these intention models. We then provide theoretical insights on role models in an entrepreneurship context and hypothesize that role models (a) directly 
Accepted Author Manuscript: Electronic version of an article published as Journal of Enterprising Culture 2018 26:02, 113-153 [https://doi.org/10.1142/S021849581850005X] C) [copyright World Scientific Publishing Company] [https://www.worldscientific.com/doi/abs/10.1142/S021849581850005X]

"I Want to Be Like You!": The Influence of Role Models on Entrepreneurial Intention

Katharina Fellnhofer (LUT School of Business and Management, Lappeenranta University of Technology, P. O. Box 20, 53851 Lappeenranta, Finland) and

Susan Mueller (Swiss Research Institute of Small Business and Entrepreneurship University of St. Gallen, Dufourstrasse 40a, 9000 St. Gallen, Switzerland)

influence antecedents of EI and (b) have a mediating effect on EI via these antecedents. We then present our research methods and results. This is followed by a discussion of the theoretical and practical implications of these findings. Finally, we discuss the limitations of and further research avenues suggested by our work.

\section{Theoretical Background and Hypotheses}

In a seminal article, Bird (1988) convincingly described the significance of entrepreneurs' intentions: While inspiration might provide the spark for a new product or service idea, it takes sustained intention to initiate new venture development. Consequently, intention is a key ingredient in entrepreneurial behavior. Entrepreneurs' intentions direct attention, experience, and action toward new venture development or the creation of new value in existing businesses. They guide issues such as goal setting, communication, commitment, and organization (Bird 1988, p. 442).

For these reasons, EI, which can be defined as the intention to found a company (e.g., Kolvereid 1996a; Krueger, Reilly, and Carsrud 2000; Tegtmeier 2006), has received considerable attention in entrepreneurship research and has been described as the best predictor of any planned behavior, including entrepreneurship (Krueger, Reilly, and Carsrud 2000). Intentions capture motivational factors that influence a certain behavior and thus indicate how much effort someone is willing to exert to perform the respective behavior (Ajzen 1991). In other words, intentionality is a "state of mind that helps to direct a person's attention (and therefore experience and action) toward a specific object (goal) or a path in order to achieve something (means)" (Bird 1988, p. 442).

In entrepreneurship, two intention models have been used intensively: the TPB, which was developed and tested in the field of social psychology (Ajzen 1991), and the EEM, which stems from 
Accepted Author Manuscript: Electronic version of an article published as Journal of Enterprising Culture 2018 26:02, 113-153 [https://doi.org/10.1142/S021849581850005X] C) [copyright World Scientific Publishing Company] [https://www.worldscientific.com/doi/abs/10.1142/S021849581850005X]

"I Want to Be Like You!": The Influence of Role Models on Entrepreneurial Intention

Katharina Fellnhofer (LUT School of Business and Management, Lappeenranta University of Technology, P. O. Box 20, 53851 Lappeenranta, Finland) and

Susan Mueller (Swiss Research Institute of Small Business and Entrepreneurship University of St. Gallen, Dufourstrasse 40a, 9000 St. Gallen, Switzerland)

entrepreneurship research (Shapero, and Sokol 1982). Additionally, Koenig and Schloegel (2013) recently introduced an integrated version of the two models. We want to test the influence of role models with all three intentions models. However, before we include the role model as another antecedent to these models, we will first test the validity of the aforementioned intention models stepwise.

\section{Theory of Planned Behavior and Entrepreneurial Event Model}

TPB is widely used in different areas, including psychology (e.g., Hashim, Jawis, Wahat, and Grove 2014; Williamson, and Lawson 2015; Lheureux, Auzoult, Charlois, Hardy-Massard, and Minary 2016), biology (e.g., Sagas, Cunningham, and Pastore 2006; Hamilton, Cox, and White 2012), and for therapeutic use in the health sciences (e.g., Agarwal 2014; Catalano, Knowlden, Birch, Leeper, Paschal, and Usdan 2017). It remains the most commonly used predictive model to analyze human intentions today (Krueger Jr 2017).

The TPB claims that intentions to perform a planned behavior, together with perceptions of behavioral control, account for substantive variance in actual behavior (Ajzen, 1991). The theory proposes that the intention to perform a planned behavior can be predicted from the attitudes toward the respective behavior, subjective norms, and perceived behavioral control. Attitudes toward the behavior deal with beliefs about the likely outcomes of the respective behavior and the evaluation of these outcomes (Ajzen 2002, p. 1). Subjective norms refer to an individual's perception of the normative expectations of others relevant to the individual and the person's motivation to follow these expectations. Perceived behavioral control (PBC) refers to someone's perception of the ease or difficulty of performing the behavior in question. Interestingly, this perceived control 
Accepted Author Manuscript: Electronic version of an article published as Journal of Enterprising Culture 2018 26:02, 113-153 [https://doi.org/10.1142/S021849581850005X] C) [copyright World Scientific Publishing Company] [https://www.worldscientific.com/doi/abs/10.1142/S021849581850005X]

"I Want to Be Like You!": The Influence of Role Models on Entrepreneurial Intention

Katharina Fellnhofer (LUT School of Business and Management, Lappeenranta University of Technology, P. O. Box 20, 53851 Lappeenranta, Finland) and

Susan Mueller (Swiss Research Institute of Small Business and Entrepreneurship University of St. Gallen, Dufourstrasse 40a, 9000 St. Gallen, Switzerland)

is more important than the actual control over the behavior of interest (Ajzen, 1991, p. 183).

In addition, to the three constructs included in the original model we also included entrepreneurial self-efficacy (ESE) in our model. Using either PBC or ESE is one of the most discussed topics in TPB literature. While in earlier years Ajzen (1991) treats it as two constructs, the close relationship between these two dimensions has been emphasized recently (Ajzen 2002). The uncertainty regarding when to use PBC or ESE provoked the supplementing use of the dimensions in the EI literature (Schlaegel, and Koenig 2013). We therefore included ESE in our model as an additional construct of TPB. Moreover, Schlaegel and Koenig (2013) presented prior studies which examined entrepreneurial self-efficacy with both models - the EEM (e.g., Byabashaija, and Katono 2011; Lucas, and Cooper 2012; Shook, and Bratianu 2010) and the TPB (e.g., Carr, and Sequeira 2007; Engle, Dimitriadi, Gavidia, Schlaegel, Delanoe, Alvarado, He, Buame, and Wolff 2010; Kolvereid, and Isaksen 2006).

For the first step in our empirical study, we wanted to confirm earlier results regarding the predictive power of the TPB and suggested the following hypothesis:

Hypothesis 1: Attitudes, subjective norms, entrepreneurial self-efficacy, and perceived behavioral control are positively related to entrepreneurial intention.

When Shapero and Sokol (1982) introduced the EMM, the two authors tried to understand two issues: the triggers that caused people to change their life and why people choose a particular career path among countless other options. With regard to the second question, they found that two drivers play a key role: perceptions of desirability and perceptions of feasibility. 
Accepted Author Manuscript: Electronic version of an article published as Journal of Enterprising Culture 2018 26:02, 113-153 [https://doi.org/10.1142/S021849581850005X] C) [copyright World Scientific Publishing Company] [https://www.worldscientific.com/doi/abs/10.1142/S021849581850005X]

"I Want to Be Like You!": The Influence of Role Models on Entrepreneurial Intention

Katharina Fellnhofer (LUT School of Business and Management, Lappeenranta University of Technology, P. O. Box 20, 53851 Lappeenranta, Finland) and

Susan Mueller (Swiss Research Institute of Small Business and Entrepreneurship University of St. Gallen, Dufourstrasse 40a, 9000 St. Gallen, Switzerland)

Perceived desirability captures the perceived attractiveness of a specific behavior, while perceived feasibility is the perceived capacity to carry out the respective behavior (Liñán, and Santos 2007: p. 445). Both concepts are shaped by cultural and social environments. Perceptions of desirability are shaped through culture, family, colleagues, or mentors. With regard to culture, it can be observed, for instance, that persons living in a social system that values new venture formation will be more likely to become entrepreneurs (Shapero, and Sokol 1982). Family can also play an important role in the process of establishing desirability. Studies show that the percentage of entrepreneurs is much higher among people whose parents are entrepreneurs themselves. However, peers, classmates, and colleagues with an entrepreneurial career can also influence perceived desirability (Shapero, and Sokol 1982).

The factors that influence feasibility perceptions are financial support, demonstration effects, models, mentors, and partners. Financial resources are an obvious necessity. Demonstration effects and models show that the starting of a business is manageable. Furthermore, the belief that mentors and partners provide support during the founding stage can increase perceived feasibility (Shapero, and Sokol 1982).

It is worth mentioning that a high level of EI requires both a high level of perceived desirability and a high level of feasibility: "If one perceives that the formation of a company is unfeasible, one may conclude it is undesirable. If one perceives the act as undesirable, one may never consider its feasibility" (Shapero, and Sokol 1982: p. 86).

For the second step in our empirical study, we wanted to confirm the relationships suggested by the EEM and proposed the following hypothesis: 
Accepted Author Manuscript: Electronic version of an article published as Journal of Enterprising Culture 2018 26:02, 113-153 [https://doi.org/10.1142/S021849581850005X] C) [copyright World Scientific Publishing Company] [https://www.worldscientific.com/doi/abs/10.1142/S021849581850005X]

"I Want to Be Like You!": The Influence of Role Models on Entrepreneurial Intention

Katharina Fellnhofer (LUT School of Business and Management, Lappeenranta University of Technology, P. O. Box 20, 53851 Lappeenranta, Finland) and

Susan Mueller (Swiss Research Institute of Small Business and Entrepreneurship University of St. Gallen, Dufourstrasse 40a, 9000 St. Gallen, Switzerland)

\section{Hypothesis 2: Perceived desirability and perceived feasibility are positively related to EI.}

\section{The Influence of Role Models on Entrepreneurial Intention}

Role modeling occurs when social behavior is detected and approved by an individual. Consequently, the learner learns by example and not by their own experience (Bandura, 1977). Several previous studies have discussed the positive relationship between observing an entrepreneurial role model and an entrepreneurial career choice. Studies have, for example, observed the impact of parental role models and shown that they are indeed associated with expectancy for an entrepreneurial career (Scherer, Adams, Carley, \& Wiebe, 1989). Chlosta et al. (2012) examined the influence of parental role models in entrepreneurial families. Drawing on a sample of 461 alumni from eight German universities, they showed that a parental role model increased the likelihood that individuals become self-employed.

With regard to the EIs of school students', Rosique-Blasco et al. (2016) conducted an empirical study with a sample of 1,244 secondary school students from Spain (average age 15 years old) to examine how skills related to entrepreneurship and entrepreneurial role models can influence the way in which secondary students choose an entrepreneurial career. The authors showed that those individuals who have an entrepreneurial role model are more prone to choose an entrepreneurial career than others.

Various studies have also - empirically or conceptually — discussed the influence of role models on students' career intentions. For example, Scherer et al. (1989), Krueger and Carsrud (1993), and Krueger et al. (2000) claim that entrepreneurial role models can encourage EI. However, they 
Accepted Author Manuscript: Electronic version of an article published as Journal of Enterprising Culture 2018 26:02, 113-153 [https://doi.org/10.1142/S021849581850005X] C [copyright World Scientific Publishing Company] [https://www.worldscientific.com/doi/abs/10.1142/S021849581850005X]

"I Want to Be Like You!": The Influence of Role Models on Entrepreneurial Intention

Katharina Fellnhofer (LUT School of Business and Management, Lappeenranta University of Technology, P. O. Box 20, 53851 Lappeenranta, Finland) and

Susan Mueller (Swiss Research Institute of Small Business and Entrepreneurship University of St. Gallen, Dufourstrasse 40a, 9000 St. Gallen, Switzerland)

state that this is only the case if one's entrepreneurial attitudes and PBC is impacted. More specifically, Kolvereid (1996a) claims that entrepreneurial role models can indirectly affect EI via their effect on the antecedents of career intentions such as entrepreneurial attitudes, subjective norms, and PBC.

The logic behind the effect of role models on behavior control is explained by Wood and Bandura (1989), who postulate that entrepreneurial role models build beliefs in observers' abilities by passing on effective approaches for coping with different entrepreneurial situations. Entrepreneurial role models can therefore increase perceived behavioral control by strengthening one's perceptions of the necessary ability to cope with entrepreneurial challenges. Scholars such as BarNir et al. (2011) and Scherer et al. (1989) also stress that entrepreneurial role models positively influence one's PBC. On the contrary, Zellweger et al. (2011) empirically showed that students with a family business background are optimistic about their entrepreneurial capabilities and resources to pursue an entrepreneurial career, meaning that an entrepreneurial career path seemed feasible. Interestingly, this did not translate into higher EI. As argued by the authors, one reason could be that students vicariously experience the negative sides of running a business, such as personal sacrifices. Consequently, and in line with Bandura (1997), entrepreneurial role models are anticipated to impact PBC.

A positive effect of role models has also been observed with regard to self-efficacy. BarNir et al. (2011) explored the effect of exposure to role models and entrepreneurial career intention. They observed a direct, yet mediating effect of exposure to role models on entrepreneurial career intention. 
Accepted Author Manuscript: Electronic version of an article published as Journal of Enterprising Culture 2018 26:02, 113-153 [https://doi.org/10.1142/S021849581850005X] C [copyright World Scientific Publishing Company] [https://www.worldscientific.com/doi/abs/10.1142/S021849581850005X]

"I Want to Be Like You!": The Influence of Role Models on Entrepreneurial Intention

Katharina Fellnhofer (LUT School of Business and Management, Lappeenranta University of Technology, P. O. Box 20, 53851 Lappeenranta, Finland) and

Susan Mueller (Swiss Research Institute of Small Business and Entrepreneurship University of St. Gallen, Dufourstrasse 40a, 9000 St. Gallen, Switzerland)

The determinant "subjective norms" comprises the beliefs absorbed from family members, relatives, friends and other important (groups of) individuals. Based on Ajzen (1991), the values of these persons and the connected social pressure impacts one's power to act. In this context, Heuer and Liñán (2013) tested further measurements of subjective norms in models using EI. While scholars provided support for the encouraging connection between role models and career choices (Van Auken, Fry, and Stephens 2006), previous studies proposed to include intervening dimensions (BarNir, Watson, and Hutchins 2011). Kolvereid (1996b) showed that role models encourage intentions indirectly by influencing the antecedents of intentions, namely subjective norms, among others. This notion is also supported by previous research regarding the positive effects of entrepreneurial role models on the dimensions of TPB (e.g. Scherer, Brodzinski, and Wiebe 1991; Krueger 1993; Nauta, and Kokaly 2001). Obviously, role models affect subjective norms via social influence by supporting encouragement. This prediction is based on social cognitive theory (Bandura 1986).

Based on the multiple studies claiming the positive effect of role models on attitudes, subjective norms, and perceptions, we therefore hypothesize the following:

Hypothesis 3: Entrepreneurial role models are positively related to attitudes, subjective norms, entrepreneurial self-efficacy, and perceived behavioral control.

Hypothesis 4: Entrepreneurial role models are positively related to desirability and feasibility.

\section{The Influence of Role Models on an Integrated Entrepreneurial Intention Model}

Schlaegel and Koenig (2013) used a meta-analytical study to examine the empirical fit of TPB and EEM and an integrated model that combines both theories. They found that all three models 
Accepted Author Manuscript: Electronic version of an article published as Journal of Enterprising Culture 2018 26:02, 113-153 [https://doi.org/10.1142/S021849581850005X] C [copyright World Scientific Publishing Company] [https://www.worldscientific.com/doi/abs/10.1142/S021849581850005X]

"I Want to Be Like You!": The Influence of Role Models on Entrepreneurial Intention

Katharina Fellnhofer (LUT School of Business and Management, Lappeenranta University of Technology, P. O. Box 20, 53851 Lappeenranta, Finland) and

Susan Mueller (Swiss Research Institute of Small Business and Entrepreneurship University of St. Gallen, Dufourstrasse 40a, 9000 St. Gallen, Switzerland)

fit empirically, but that the integrated model provides additional explanatory power and a more comprehensive understanding of the process through which EI develop. We therefore decided to also analyze the impact of role models on EI through the integrated model provided by Koenig and Schloegel (1993) and thus to give voice to the following hypotheses. A graphical representation of the hypotheses is provided in Figure 1.

Hypothesis 5a: Entrepreneurial role models are positively related to attitudes, subjective norms, entrepreneurial self-efficacy, and perceived behavioral control.

Hypothesis 5b: Attitudes, subjective norms, entrepreneurial self-efficacy, and perceived behavioral control are positively related to perceived desirability.

Hypothesis 5c: Entrepreneurial self-efficacy and perceived behavioral control are positively related to perceived feasibility.

\section{"Insert Figure 1 Here"}

\section{Method}

To measure the effects of role models on the TPB and EEM model, we build our analysis on a well-established research design. Basically, previous investigations have revealed that observing entrepreneurial role models is positively associated with EI (e.g., Krueger et al. 2000; van Auken et al. 2006). However, these discussions remain silent about the impact of entrepreneurial role models on each variable in the different well-established models at the same time. Schlaegel and Koenig (2013) argue that a study investigating both models TBP and EEM at the same time allows a focused empirical research to embrace the whole picture of different interrelationships between 
Accepted Author Manuscript: Electronic version of an article published as Journal of Enterprising Culture 2018 26:02, 113-153 [https://doi.org/10.1142/S021849581850005X] C) [copyright World Scientific Publishing Company] [https://www.worldscientific.com/doi/abs/10.1142/S021849581850005X]

"I Want to Be Like You!": The Influence of Role Models on Entrepreneurial Intention

Katharina Fellnhofer (LUT School of Business and Management, Lappeenranta University of Technology, P. O. Box 20, 53851 Lappeenranta, Finland) and

Susan Mueller (Swiss Research Institute of Small Business and Entrepreneurship University of St. Gallen, Dufourstrasse 40a, 9000 St. Gallen, Switzerland)

the underlying variables of the well-established models. We followed this recommendation to understand in detail how entrepreneurial role models impact these relationships incrementally. To understand in a comprehensive and gradual manner via which antecedents entrepreneurial role models affect EI we explored the impact of role models step-by-step using first the individuals models TBP, EEM and then the integrated version of the two models.

In this section, we first discuss the underlying research setting and sample characteristics. We then describe the measurements of control variables. Further descriptive statistics are presented in Section 4 along with the results of the analysis.

\section{Research Settings and Sample Characteristics}

Data collection took place between February 2016 and May 2017 with students located in Austria, Finland, and Greece. Selected students of universities and vocational schools were randomly chosen. Some of the students filled out the online questionnaire during a class session, while others filled out the questionnaire at home. In total, 426 individuals filled out a questionnaire. We then excluded 160 questionnaires that were only filled out carelessly (same answers across multiple scales of the questionnaire). We performed a comprehensive confirmatory factor analysis (CFA) (see Table 9, Appendix) to ensure that no measurement and model systematic error pertaining to our variables. Finally, we analyzed 266 questionnaires. The respondents are students from different universities located in Finland $(n=69)$, Austria $(n=92)$, Greece $(n=79)$, and other countries ( $=26)$. The three-country average of the population by sex is $39 \%$ female and $61 \%$ male.

"Insert Table 1 Here" 
Accepted Author Manuscript: Electronic version of an article published as Journal of Enterprising Culture 2018 26:02, 113-153 [https://doi.org/10.1142/S021849581850005X] C) [copyright World Scientific Publishing Company] [https://www.worldscientific.com/doi/abs/10.1142/S021849581850005X]

"I Want to Be Like You!": The Influence of Role Models on Entrepreneurial Intention

Katharina Fellnhofer (LUT School of Business and Management, Lappeenranta University of Technology, P. O. Box 20, 53851 Lappeenranta, Finland) and

Susan Mueller (Swiss Research Institute of Small Business and Entrepreneurship University of St. Gallen, Dufourstrasse 40a, 9000 St. Gallen, Switzerland)

Measurements. We employed multi-item scales altered from preceding studies as measurement instruments. We provide the reliability of the scales in Table 2 which indicates that all scales fulfill the recommended requirements being discussed in more detail hereafter. As mentioned below we adapted most of the scales to our context. All of these changes were minor adjustments. For example, we included the word "entrepreneurial" to items of the role model scale provided by Nauta and Kokaly (2001): "There is an entrepreneurial person I am trying to be like in my career pursuits". Role model. We adapted a five-item scale from Nauta and Kokaly (2001) to measure inspiration / modeling of an entrepreneurial role model. Entrepreneurial attitudes. We modified the sixitem scale from Liñán and Chen (2009) to measure attitudes. Subjective norms. We adapted the four-item-scale from Liñán and Chen (2009) and Kautonen et al. (2013) to measure who in one's close environment approves the decision to create a firm. Our data confirmed the reliability of the scale. Perceived behavioral control. We modified the six-item scale from Liñán and Chen (2009) measuring PBC. Using this scale, the individual has to express his or her agreement with statements such as "To start a firm and keep it working would be easy for me" or "I am prepared to start a viable firm" or "If I tried to start a firm, I would have a high probability of succeeding". Entrepreneurial self-efficacy. We applied the ten-item scale previously used by Chen, Gully, and Eden 2001) and Kickul, Gundry, Barbosa, and Whitcanack 2009) and performed minor adjustment with regard to the wording. General self-efficacy relates to "one's estimate of one's overall ability to perform successfully in a wide variety of achievement situations" (Chen, Gully, and Eden 2001, p. 79), or to "how confident one is that she or he can perform effectively across different tasks and 
Accepted Author Manuscript: Electronic version of an article published as Journal of Enterprising Culture 2018 26:02, 113-153 [https://doi.org/10.1142/S021849581850005X] C) [copyright World Scientific Publishing Company] [https://www.worldscientific.com/doi/abs/10.1142/S021849581850005X]

"I Want to Be Like You!": The Influence of Role Models on Entrepreneurial Intention

Katharina Fellnhofer (LUT School of Business and Management, Lappeenranta University of Technology, P. O. Box 20, 53851 Lappeenranta, Finland) and

Susan Mueller (Swiss Research Institute of Small Business and Entrepreneurship University of St. Gallen, Dufourstrasse 40a, 9000 St. Gallen, Switzerland)

situations" (Chen, Gully, and Eden 2001, p. 63). Entrepreneurial self-efficacy captures the confidence of a person to perform the activities necessary to start a company. Perceived desirability. We adapted the scale from Peterman and Kennedy (2003), consisting of three items. Our data stressed the reliability of this scale. Perceived feasibility. Five items measuring feasibility have been also taken from Peterman and Kennedy (2003). In this regard, the suggested threshold of 0.70 has not been met with Cronbach's $\alpha$ of 0.674 (Nunnally 1978; Hair, Anderson, Tatham, and Black 1995). However, according to Loewenthal (2004), a threshold above 0.6 is still acceptable. Entrepreneurial intention. Items associated with EI were taken from Liñán and Chen (2009). Participants indicated their level of agreement with each item from one (strongly disagree) to seven (strongly agree)

\section{"Insert Table 2 Here"}

Control variables. We controlled for demographic and background variables such as age, gender, nationality, and entrepreneurial experience. We selected the control variables for the following reasons: Respondents' age represents a controlling variable, because older people are less likely to become entrepreneurs than younger people (Levesque, and Minniti 2006). Gender is also a controlling variable, as more enterprises have been established by males than by females thus far (Brush 1992; Herrington, and Kew 2017) and prior studies recommend paying extra attention to gender-related differences, particularly in entrepreneurship education, for instance (e.g. Shinnar et al. 2014; Kelley et al. 2016; Fellnhofer, Puumalainen, and Sjögrén 2016). Nationality was implemented as a control variable, as investment in human capital can improve the return on investment from entrepreneurship on a national level (Unger, Rauch, Frese, and Rosenbusch 2011). Finally, 
Accepted Author Manuscript: Electronic version of an article published as Journal of Enterprising Culture 2018 26:02, 113-153 [https://doi.org/10.1142/S021849581850005X] C) [copyright World Scientific Publishing Company] [https://www.worldscientific.com/doi/abs/10.1142/S021849581850005X]

"I Want to Be Like You!": The Influence of Role Models on Entrepreneurial Intention

Katharina Fellnhofer (LUT School of Business and Management, Lappeenranta University of Technology, P. O. Box 20, 53851 Lappeenranta, Finland) and

Susan Mueller (Swiss Research Institute of Small Business and Entrepreneurship University of St. Gallen, Dufourstrasse 40a, 9000 St. Gallen, Switzerland)

we controlled for entrepreneurial experience as role models could have different effects on individuals with different levels of experience (e.g., Arenius, and Minniti 2005; Wagner, and Sternberg 2004; Zampetakis, Lerakis, Kafetsios, and Moustakis 2015). In this regard we applied a 8-itemscale of Peterman and Kennedy (2003) with following yes/no questions "Have your parents ever started a business?", "Has another family member ever started a business?", "Has a friend of you ever started a business?", "Has another important person in your life ever started a business?", "Have you ever worked for a small or new company?", "Have you ever started a business?", "Do you have work experience?" and "Do you have any other entrepreneurial/ self-employed experience?".

\section{Results}

To examine the research question, we applied several data analysis methods in multiple waves. Table 3 depicts means, standard deviations (SD), and correlations of the variables in the models. Since none of the correlations surpass 0.7 , there is no significant risk of multicollinearity (Anderson, Sweeney, and T.A. 2002). Additionally, the variance inflation factor (VIF) for each independent variable was performed to guarantee that it is under 2.5 (Allison 1999). Finally, multicollinearity is not an issue in this study.

\section{"Insert Table 3 Here"}

Structural Equation Modeling. To inspect the entrepreneurial role models as an antecedent of both the TPB, the EEM, and the nested model and each model separately, we applied structural equation modeling. This modeling allows us to examine relationships between different theories. Schlaegel and Koenig (2013) stressed that there is no individual study that has been published so 
Accepted Author Manuscript: Electronic version of an article published as Journal of Enterprising Culture 2018 26:02, 113-153 [https://doi.org/10.1142/S021849581850005X] C) [copyright World Scientific Publishing Company] [https://www.worldscientific.com/doi/abs/10.1142/S021849581850005X]

"I Want to Be Like You!": The Influence of Role Models on Entrepreneurial Intention

Katharina Fellnhofer (LUT School of Business and Management, Lappeenranta University of Technology, P. O. Box 20, 53851 Lappeenranta, Finland) and

Susan Mueller (Swiss Research Institute of Small Business and Entrepreneurship University of St. Gallen, Dufourstrasse 40a, 9000 St. Gallen, Switzerland)

far that included both constructs - TPB and EEM — at the same time. Consequently, this study presents the most appropriate statistical approach for testing entrepreneurial role models impact on these competing theories (Viswesvaran, and Ones 1995; Hedges 2009; Leavitt, Mitchell, and Peterson 2010).

Additionally, this study follows the recommendations of colleagues Hair et al. (2010) and Kline (2005)), who claim that structural equation modeling should be performed in two steps. The first step assesses the measurement model. The second step evaluates the proposed structural model. We applied AMOS 22 with maximum likelihood estimation to test the path models. Multiple additional indicators have been used to evaluate model fit, namely chi-square $\left(\chi^{2}\right)$, goodness-of-fit Index (GFI), comparative fit index (CFI), Tucker Lewis index (TLI), incremental fit index (IFI) and root mean square residual (RMSEA). Age, gender, nationality, and entrepreneurial experience have paths to both independent and dependent variables.

Hypothesis 1. Testing the theory of planned behavior. We illustrated the results of the analyses for testing the TPB model in Table 4. The relationships between entrepreneurial attitudes and EI $(\mathrm{SRW}=0.529, \mathrm{p}<.001)$ and between perceived behavioral control and $\mathrm{EI}(\mathrm{SRW}=0.400, \mathrm{p}<.001)$ are positive and statistically significant. The results of these variables are comparable with metaanalytic research in terms of the strength of the effect sizes (Armitage, and Conner 2001; ATB: SRW $=0.49 ;$ PBC: SRW =0.43). Only subjective norm $(\mathrm{SRW}=-0.016$, n.s. $)$ and self-efficacy $(\mathrm{SRW}=-0.042$, n.s. $)$ are not statistically significant. These findings support prior contributions discussing self-efficacy and perceived behavioral control as concepts that are related but differ significantly in their effect on EI (Conner, and Armitage 1998; Ajzen 2002). Overall, the TPB has a 
Accepted Author Manuscript: Electronic version of an article published as Journal of Enterprising Culture 2018 26:02, 113-153 [https://doi.org/10.1142/S021849581850005X] C) [copyright World Scientific Publishing Company] [https://www.worldscientific.com/doi/abs/10.1142/S021849581850005X]

"I Want to Be Like You!": The Influence of Role Models on Entrepreneurial Intention

Katharina Fellnhofer (LUT School of Business and Management, Lappeenranta University of Technology, P. O. Box 20, 53851 Lappeenranta, Finland) and

Susan Mueller (Swiss Research Institute of Small Business and Entrepreneurship University of St. Gallen, Dufourstrasse 40a, 9000 St. Gallen, Switzerland)

high explanatory power: Our model explains $61 \%$ of the variance in EI and the model fits the data well $\left(\chi^{2}=1043,892 ; \chi^{2} / \mathrm{df}=1.79 ; \mathrm{GFI}=0.826 ; \mathrm{CFI}=0.905 ; \mathrm{TLI}=0.891 ; \mathrm{IFI}=0.906 ; \mathrm{RMSEA}=\right.$ 0.055). As a result, our outcomes are not fully in line with prior research (Armitage, and Conner 2001; Notani 1998), which showed that all determinants proposed by the TPB have significant effects in explaining intention toward performing a particular behavior. We conclude that hypothesis $1 \mathrm{a}$ - attitudes, subjective norms, entrepreneurial self-efficacy, and PBC are positively related to EI - is partially supported.

\section{"Insert Table 4 Here"}

Referring to the control variables, age shows a significant path to perceived behavioral control $(\mathrm{SRW}=0.136, \mathrm{p}<.05)$. The older the individual, the higher the perceived behavioral control. Furthermore, gender has a significant path to perceived behavioral control (SRW $=-0.153, \mathrm{p}<$ .05 ) and self-efficacy (SRW $=-0.177, \mathrm{p}<.05)$. In other words, females assess both their perceived behavioral control and self-efficacy lower than their male counterparts. Next, entrepreneurial experience is significant to self-efficacy (SRW $=0.249, \mathrm{p}<.001$ ), perceived behavioral control $(\mathrm{SRW}=0.280, \mathrm{p}<.001)$, and entrepreneurial attitudes $(\mathrm{SRW}=0.308, \mathrm{p}<.001)$, meaning that individuals with less entrepreneurial experience also perceive lower levels of self-efficacy, perceived behavioral control, and entrepreneurial attitudes.

Hypothesis 2. Testing the entrepreneurial event model. Results of the analyses for the EEM are illustrated in Table 5. The relationships between EI and perceived desirability (SRW $=0.652, \mathrm{p}<$ $.001)$ and between EI and perceived feasibility $(\mathrm{SRW}=0.233, \mathrm{p}<.001)$ are positive and statistically significant. Perceived desirability and perceived feasibility have a significant and positive 
Accepted Author Manuscript: Electronic version of an article published as Journal of Enterprising Culture 2018 26:02, 113-153 [https://doi.org/10.1142/S021849581850005X] C) [copyright World Scientific Publishing Company] [https://www.worldscientific.com/doi/abs/10.1142/S021849581850005X]

"I Want to Be Like You!": The Influence of Role Models on Entrepreneurial Intention

Katharina Fellnhofer (LUT School of Business and Management, Lappeenranta University of Technology, P. O. Box 20, 53851 Lappeenranta, Finland) and

Susan Mueller (Swiss Research Institute of Small Business and Entrepreneurship University of St. Gallen, Dufourstrasse 40a, 9000 St. Gallen, Switzerland)

effect and explain $62 \%$ of the variance in EI. The findings therefore stress that perceived desirability and perceived feasibility are significant determinants of EI within the EEM. Consequently, our hypothesis $2 \mathrm{a}$ - that perceived desirability and perceived feasibility are positively related to EI - is supported.

\section{"Insert Table 5 Here”}

We observed the following with regard to the control variables. Overall, females tend to show significantly lower levels of perceived desirability ( $\mathrm{SRW}=-0.340, \mathrm{p}<.1)$ and perceived feasibility $(\mathrm{SRW}=-0.295, \mathrm{p}<.05)$ than males. Furthermore, entrepreneurial experience significantly influences perceived desirability (SRW $=0.748, \mathrm{p}<.001)$, perceived feasibility $(\mathrm{SRW}=0.446, \mathrm{p}<$ $.01)$, and $\operatorname{EI}(\mathrm{SRW}=0.255, \mathrm{p}<.1)$. In other words, individuals with less entrepreneurial experience tend to show lower levels of perceived desirability, perceived feasibility, and EI. Compared to students from Austria, Finnish students tend to have significantly lower levels of EI (SRW $=-0.28$, $\mathrm{p}<.05$ ). While Greek students tend to show higher levels of perceived desirability than Austrian students (SRW $=0.491, \mathrm{p}<.05)$, perceived feasibility in Greece is significantly lower than in Austria $(\mathrm{SRW}=-0.453, \mathrm{p}<.01)$.

Hypothesis 3. Testing entrepreneurial role models as an antecedent of the theory of planned behavior. To test hypothesis 3 , the results for the main relationships of the models are summarized in Table 6a, Table 6b, and Table 6c. The results of the analyses between role model and TPB are all positive and statistically significant, such as role model and entrepreneurial attitudes (SRW = $0.414, \mathrm{p}<.001$ ), role model and subjective norms (SRW $=0.331, \mathrm{p}<.001$ ), role model and selfefficacy $(\mathrm{SRW}=0.287, \mathrm{p}<.001$ ), and role model and perceived behavioral control $(\mathrm{SRW}=0.175$, 
Accepted Author Manuscript: Electronic version of an article published as Journal of Enterprising Culture 2018 26:02, 113-153 [https://doi.org/10.1142/S021849581850005X] C) [copyright World Scientific Publishing Company] [https://www.worldscientific.com/doi/abs/10.1142/S021849581850005X]

"I Want to Be Like You!": The Influence of Role Models on Entrepreneurial Intention

Katharina Fellnhofer (LUT School of Business and Management, Lappeenranta University of Technology, P. O. Box 20, 53851 Lappeenranta, Finland) and

Susan Mueller (Swiss Research Institute of Small Business and Entrepreneurship University of St. Gallen, Dufourstrasse 40a, 9000 St. Gallen, Switzerland)

$\mathrm{p}<.001)$. Hypothesis 3 , stating that entrepreneurial role models are positively related to attitudes, subjective norms, ESE, and PBC, was therefore accepted.

\section{"Insert Table 6a Here"}

With regard to our control variables, individuals with more entrepreneurial experience show higher values in entrepreneurial attitudes $(\mathrm{SRW}=0.155, \mathrm{p}<.05)$, higher values in perceived behavioral control $(\mathrm{SRW}=0.226, \mathrm{p}<.01)$, and higher values in self-efficacy $(\mathrm{SRW}=0.156, \mathrm{p}<$ .05). In Finland, subjective norms show significantly higher results than in Austria (SRW $=0.222$, $\mathrm{p}<.01$ ). This holds true for self-efficacy (SRW $=0.247, \mathrm{p}<.01$ ). While Greek individuals show higher results for self-efficacy (SRW $=0.195, \mathrm{p}<.05$ ), Finnish students show significantly lower results in EI compared to Austria (SRW $=-0.126, \mathrm{p}<.05$ ). Furthermore, females tend to perceive lower rates of self-efficacy than males $(\mathrm{SRW}=-0.161, \mathrm{p}<.05)$.

\section{Hypothesis 4. Testing entrepreneurial role models as an antecedent of the entrepreneurial event} model. Table $6 \mathrm{~b}$ provides an overview of relationships for the EEM including role models. Both paths role model and perceived desirability $(\mathrm{SRW}=0.342, \mathrm{p}<.001)$ and role model and perceived feasibility $(\mathrm{SRW}=0.149, \mathrm{p}<.1$ ) are positive and significant. Additionally, perceived desirability $(\mathrm{SRW}=0.680, \mathrm{p}<.001)$ and perceived feasibility $(\mathrm{SRW}=0.270, \mathrm{p}<.001)$ significantly influence EI. Furthermore, individuals with more entrepreneurial experience show higher levels of perceived feasibility $(\mathrm{SRW}=0.171, \mathrm{p}<.05)$ and higher levels of inspiration from the role models $(\mathrm{SRW}=$ $0.316, p<.001)$. Overall, females tend to show significantly lower levels of perceived desirability $(\mathrm{SRW}=-0.122, \mathrm{p}<.05)$ and perceived feasibility $(\mathrm{SRW}=-0.161, \mathrm{p}<.05)$ than males. In addition, older individuals show higher levels of perceived feasibility ( $\mathrm{SRW}=0.156, \mathrm{p}<.05$ ). Finally, while 
Accepted Author Manuscript: Electronic version of an article published as Journal of Enterprising Culture 2018 26:02, 113-153 [https://doi.org/10.1142/S021849581850005X] C) [copyright World Scientific Publishing Company] [https://www.worldscientific.com/doi/abs/10.1142/S021849581850005X]

"I Want to Be Like You!": The Influence of Role Models on Entrepreneurial Intention

Katharina Fellnhofer (LUT School of Business and Management, Lappeenranta University of Technology, P. O. Box 20, 53851 Lappeenranta, Finland) and

Susan Mueller (Swiss Research Institute of Small Business and Entrepreneurship University of St. Gallen, Dufourstrasse 40a, 9000 St. Gallen, Switzerland)

the levels of perceived feasibility in Greece $(\mathrm{SRW}=-0.221, \mathrm{p}<.01)$ tend to be lower than for Austria, the results for perceived desirability are significantly higher $(\mathrm{SRW}=0.149, \mathrm{p}<.05)$.

Overall, hypotheses 4 was accepted.

\section{"Insert Table 6b Here"}

Hypothesis 5. Testing the integrated model including role models as an antecedent of the theory of planned behavior and entrepreneurial event model. Table 6c illustrates the findings for the integrated model of EI including role models. While the results of the analyses between role models and TPB are all still positive and statistically significant — such as role model and entrepreneurial attitudes (SRW $=0.417, \mathrm{p}<.001)$, role model and subjective norms $(\mathrm{SRW}=0.347, \mathrm{p}<.001)$, role model and self-efficacy (SRW $=0.298, \mathrm{p}<.001$ ), and role model and perceived behavioral control $(\mathrm{SRW}=0.171, \mathrm{p}<.01)$ - the paths to the EEM have also not changed significantly compared to the hypothesis testing dedicated to the EEM alone. However, $\mathrm{R}^{2}$ increased to $69 \%$ for explaining perceived desirability and to $91 \%$ for explaining perceived feasibility. Overall, $67 \%$ of the variance in EI is explained on behalf of the model. Thus, we provide enough support for hypotheses $5 \mathrm{a}, 5 \mathrm{~b}$, and $5 \mathrm{c}$.

\section{"Insert Table 6c Here”}

Regarding our control variables, individuals with more entrepreneurial experience perceive their levels of behavioral control (SRW $=0.224, \mathrm{p}<.01$ ), self-efficacy (SRW $=0.155, \mathrm{p}<.05$ ), entrepreneurial attitudes $(\mathrm{SRW}=0.155, \mathrm{p}<.05)$, and inspiration from entrepreneurial role models $(\mathrm{SRW}=0.316, \mathrm{p}<.001)$ to be significantly higher than individuals with less entrepreneurial experience. Females assess their self-efficacy $(\mathrm{SRW}=-0.175, \mathrm{p}<.01$ ) and perceived behavioral 
Accepted Author Manuscript: Electronic version of an article published as Journal of Enterprising Culture 2018 26:02, 113-153 [https://doi.org/10.1142/S021849581850005X] C) [copyright World Scientific Publishing Company] [https://www.worldscientific.com/doi/abs/10.1142/S021849581850005X]

"I Want to Be Like You!": The Influence of Role Models on Entrepreneurial Intention

Katharina Fellnhofer (LUT School of Business and Management, Lappeenranta University of Technology, P. O. Box 20, 53851 Lappeenranta, Finland) and

Susan Mueller (Swiss Research Institute of Small Business and Entrepreneurship University of St. Gallen, Dufourstrasse 40a, 9000 St. Gallen, Switzerland)

control $(\mathrm{SRW}=-0.157, \mathrm{p}<.05)$ lower than males. Furthermore, age plays a role. Older individuals show higher levels of perceived feasibility $(\mathrm{SRW}=-0.191, \mathrm{p}<.01)$, perceived behavioral control $(\mathrm{SRW}=0.156, \mathrm{p}<.05)$, and self-efficacy $(\mathrm{SRW}=0.191, \mathrm{p}<.05)$

To control the goodness-of-fit indices' reliability and validity, we conducted a CFA (see Table 9, Appendix). Overall, as indicated in Table 7, the measurement models provided a sufficient fit for the data. By assessing the measurement models, the core constructs' convergent and discriminant validities can be evaluated. Hair et al. (2010) imply that the convergent validity uses the indicators of a convergence or has a high proportion of variance in common. Fornell and Larcker (1981) explain convergent validity by using the following three steps for a measurement model: (1) Janssen et al. (2008) suggest that the loadings must have a minimum of 0.50 ; (2) Nunnally and Bernstein (1994) claim the scale composite or construct reliability must be higher than 0.70; and (3) Hair et al. (2010) suggest that for each construct the average variance extracted (AVE) must be over 0.5 . This is met for all variables except ESE and perceived feasibility. However, the composite reliability of these dimensions is higher than 0.7. Because Fornell and Larcker (1981b) said that if AVE is less than 0.5 , but composite reliability is higher than 0.6 , the convergent validity of the construct is still acceptable. Consequently, we can accept AVE for all. These requirements were achieved for all the models (see Appendix, Table 9). While all loadings were more than 0.5, which lead to sufficient convergent validity, the items specified that constructs were also significant ( $\mathrm{p}<0.01$ ). Cronbach's alpha were between 0.674 and 0.922 for all constructs. Overall, the suggested threshold of 0.70 has been met (Nunnally 1978; Hair, Anderson, Tatham, and Black 1995), with the exception of the dimension perceived feasibility. However, according to 
Accepted Author Manuscript: Electronic version of an article published as Journal of Enterprising Culture 2018 26:02, 113-153 [https://doi.org/10.1142/S021849581850005X] C [copyright World Scientific Publishing Company] [https://www.worldscientific.com/doi/abs/10.1142/S021849581850005X]

"I Want to Be Like You!": The Influence of Role Models on Entrepreneurial Intention

Katharina Fellnhofer (LUT School of Business and Management, Lappeenranta University of Technology, P. O. Box 20, 53851 Lappeenranta, Finland) and

Susan Mueller (Swiss Research Institute of Small Business and Entrepreneurship University of St. Gallen, Dufourstrasse 40a, 9000 St. Gallen, Switzerland)

Loewenthal (2004) a threshold above 0.6 is still acceptable. Finally, to test for a common method bias we took advantage of the unmeasured latent factor method approach as suggested by Podsakoff et al. (2003). All self-reported items are loaded both on their theoretical constructs and on an uncorrelated method factor. The accumulation of this factor to our constructs did not change the fit of the measurement model significantly (difference in $\chi^{2}=144.161$, difference in $\mathrm{df}=39$; $\mathrm{p}>0.05 ; \mathrm{CFI}=0.808 ; \mathrm{RMSEA}=0.047)$. In a nutshell, the results reflect enough reliability and convergent validity. Table 7 presents the summary of goodness-of-fit indices for the different models. In general, the goodness-of-fit statistics show that the data and the structural model fit very well for all of the models tested.

\section{"Insert Table 7 Here”}

\section{Discussion}

We addressed the following research question in our study: How do entrepreneurial role models affect entrepreneurial intention? To address this question, we employed a cross-sectional research design and tested our hypotheses with structure equation modeling. Our results are based on a student sample consisting of 266 individuals predominately from Austria, Finland, and Greece. In our model we introduced role models as an antecedent to the most frequently used intention models, namely the TPB, the EMM, and an integrated model of both theories as suggested by Schlaegel and Koenig (2013).

\section{"Insert Figure 2 Here"}

As illustrated in Figure 2, the results showed that role models have a positive and significant influence on EI through the antecedents described in the TPB, the EEM, and the integrated version 
Accepted Author Manuscript: Electronic version of an article published as Journal of Enterprising Culture 2018 26:02, 113-153 [https://doi.org/10.1142/S021849581850005X] C) [copyright World Scientific Publishing Company] [https://www.worldscientific.com/doi/abs/10.1142/S021849581850005X]

"I Want to Be Like You!": The Influence of Role Models on Entrepreneurial Intention

Katharina Fellnhofer (LUT School of Business and Management, Lappeenranta University of Technology, P. O. Box 20, 53851 Lappeenranta, Finland) and

Susan Mueller (Swiss Research Institute of Small Business and Entrepreneurship University of St. Gallen, Dufourstrasse 40a, 9000 St. Gallen, Switzerland)

of the two models. Tested via Hypothesis 3, entrepreneurial role models are positively related to attitudes, subjective norms, ESE, and PBC. Furthermore, as supported by Hypothesis 4, entrepreneurial role models are positively related to desirability and feasibility. In general, all of the models tested worked out very well, as confirmed by the model fit statistics. Specifically, standardized regression weights were powerful for the relationship between role models and entrepreneurial attitudes $(\mathrm{SRW}=0.417)$, role models and subjective norms $(\mathrm{SRW}=0.347)$, and role models and perceived desirability $(\mathrm{SRW}=0.342)$. In sum, our study illustrates that role models are a vital resource for changing students' entrepreneurial perceptions, which then positively influence EI. We provide an overview of all hypotheses and results in Table 8.

\section{"Insert Table 8 Here"}

\section{Theoretical Contribution and Implications}

From a theoretical perspective, the study offers three major contributions. First, we contribute to the research stream of intention models in entrepreneurship. To the best of our knowledge, such a study examining the integrated model of TBP and EEM is the first of its kind analyzing these theories in one model. In a meta-analysis, Schlaegel and Koenig (2013) called for focused empirical research to embrace the whole picture of different interrelationships between the variables of the well-established TBP and EEM (Cooper, Hedges, and Valentine 2009). In such a focused framework, as suggested, we detected and discussed the influence of particular influential perceptions such as the national context on subjective norm or gender on PBC. Second, we contribute to the research streams of role models in the context of entrepreneurship. Our investigation stresses that role models particularly matter via attitudes and $\mathrm{PBC}$. Third, we contribute to an ongoing 
Accepted Author Manuscript: Electronic version of an article published as Journal of Enterprising Culture 2018 26:02, 113-153 [https://doi.org/10.1142/S021849581850005X] C) [copyright World Scientific Publishing Company] [https://www.worldscientific.com/doi/abs/10.1142/S021849581850005X]

"I Want to Be Like You!": The Influence of Role Models on Entrepreneurial Intention

Katharina Fellnhofer (LUT School of Business and Management, Lappeenranta University of Technology, P. O. Box 20, 53851 Lappeenranta, Finland) and

Susan Mueller (Swiss Research Institute of Small Business and Entrepreneurship University of St. Gallen, Dufourstrasse 40a, 9000 St. Gallen, Switzerland)

debate dedicated to entrepreneurship education and stressing the importance of entrepreneurial identity. In the following section, we will highlight our contributions with regard to intention models before we further explain our contributions regarding the discussion of role models in entrepreneurship and entrepreneurship education.

Our article contributes to research linked to intention models since we tested the two models used most often, as well as the integrated version of both intention models. We subsequently tested the underlying theories. While Hypothesis 1 relied on the TPB as proposed by Ajzen (1991), arguing that attitudes, subjective norms, ESE, and PBC are positively related to EI, our Hypothesis 2 suggested that perceived desirability and perceived feasibility are also positively related to EI in line with the EEM as proposed by Shapero and Sokol (1982). We confirm that the relationships suggested in the models can indeed be observed and that all models, and particular the integrated model, provide high explanatory power with regard to EI.

Although we built our work on well-established models, we are faced with some unexpected results. The insignificant relationship between ESE and EI and between subjective norms and EI is not what we expected to observe. However, this is in line with previous findings from colleagues who highlighted the inconsistency of the role of subjective norms on EI (Elfving, Brännback, and Carsrud 2009; Elfving, Brännback, and Carsrud 2017). It has been argued that one reason for this could be that subjective norms are measured rather generally (Lin, Carsrud, Jagoda, and Shen 2013). Krueger and Brazeal (1994) clarified that while perceived subjective norms and perceived self-efficacy are antecedents of perceived desirability and perceived feasibility, the significant impact of subjective norms tends to not always be robust enough (Krueger, Reilly, and Carsrud 2000). 
Accepted Author Manuscript: Electronic version of an article published as Journal of Enterprising Culture 2018 26:02, 113-153 [https://doi.org/10.1142/S021849581850005X] C) [copyright World Scientific Publishing Company] [https://www.worldscientific.com/doi/abs/10.1142/S021849581850005X]

"I Want to Be Like You!": The Influence of Role Models on Entrepreneurial Intention

Katharina Fellnhofer (LUT School of Business and Management, Lappeenranta University of Technology, P. O. Box 20, 53851 Lappeenranta, Finland) and

Susan Mueller (Swiss Research Institute of Small Business and Entrepreneurship University of St. Gallen, Dufourstrasse 40a, 9000 St. Gallen, Switzerland)

As argued in prior studies (McGrath, and MacMillan 1992; Davidsson, and Wiklund 1997; Krueger, and Kickul 2006), for instance, social norms tend to vary across cultures. Indeed, our results indicate that for students from Finland the paths from subjective norms to EI ( $\mathrm{SRW}=0.255$, $\mathrm{p}<.001)$ and from self-efficacy to EI $(\mathrm{SRW}=0.271, \mathrm{p}<.001)$ are significant. Overall, while subjective norms and self-efficacy are perceived to be higher in Finland than in other countries, EI is lower. Country-specific perceptions therefore have to be analyzed with caution.

In Hypotheses 5 we proposed that attitudes, subjective norms, ESE, and PBC are positively related to perceived desirability, and that ESE and PBC are positively related to perceived feasibility. Again, role models act as an antecedent in this model. Since we found support for all the models, we recommend the application of the integrated model for further research dedicated to the influence of role models in entrepreneurship research, as it allows for a more detailed analysis of the various mechanisms.

Our study's results are in line with those of Rosique-Blasco et al. (2016), who showed that those individuals who have an entrepreneurial role model tend to have a better understanding of the entrepreneurial career path and also stress a greater tendency toward it. Previous studies have discussed the positive relationship between observing an entrepreneurial role model and an entrepreneurial career choice (e.g., BarNir, Watson, and Hutchins 2011; Chlosta, Patzelt, Klein, and Dormann 2012). However, some colleagues do not follow this notion (e.g., Franco, Haase, and Lautenschläger 2010). Overall, the exposure to entrepreneurial role models can influence one's perceptions associated with an entrepreneurial career. Our results follow Kolvereid's (1996a) claims that entrepreneurial role models can indirectly affect EI via their effect on the antecedents 
Accepted Author Manuscript: Electronic version of an article published as Journal of Enterprising Culture 2018 26:02, 113-153 [https://doi.org/10.1142/S021849581850005X] C) [copyright World Scientific Publishing Company] [https://www.worldscientific.com/doi/abs/10.1142/S021849581850005X]

"I Want to Be Like You!": The Influence of Role Models on Entrepreneurial Intention

Katharina Fellnhofer (LUT School of Business and Management, Lappeenranta University of Technology, P. O. Box 20, 53851 Lappeenranta, Finland) and

Susan Mueller (Swiss Research Institute of Small Business and Entrepreneurship University of St. Gallen, Dufourstrasse 40a, 9000 St. Gallen, Switzerland)

of career intentions such as entrepreneurial attitudes, subjective norms, and PBC. In other words, the attractiveness of becoming an entrepreneur is expected to be influenced by entrepreneurial role models. In sum, prior exposure forming entrepreneurial perceptions can significantly affect one's perceptions toward an entrepreneurial career choice.

Furthermore, as discussed in the entrepreneurship education domain, the generation of an entrepreneurial identity plays a key role (e.g. Hoang, and Gimeno 2010; Phillips, Tracey, and Karra 2013; Donnellon, Ollila, and Middleton 2014) as a stream dedicated to entrepreneurial identity to which role models could also contribute. Familiarization with others' entrepreneurial initiatives can facilitate the development of positive entrepreneurial perceptions (Carr, and Sequeira 2007). Finally, our results indicate that there is no direct effect of role models on EI, which is in line with prior findings (e.g. Scherer, Brodzinski, and Wiebe 1991; Kolvereid 1996b; Krueger, 1993) which stress that role models influence intention as exogenous variables via its antecedents.

\section{Implications for Role Model Impact Studies}

Entrepreneurship education. Research on entrepreneurship education is increasing and gaining legitimacy in scientific communities (Pittaway, and Cope 2007; Albornoz 2008; Rasmussen 2011; Lorz, Mueller, and Volery 2013). One variable that is intensively studied with regard to entrepreneurship education is EI. In entrepreneurship education research, the construct of EI plays an important role, particularly because policy-makers and educators are, of course, interested in understanding whether entrepreneurship education programs change EIs. As a result, EI has been chosen as the dependent variable in many entrepreneurship education impact studies supporting the notion 
Accepted Author Manuscript: Electronic version of an article published as Journal of Enterprising Culture 2018 26:02, 113-153 [https://doi.org/10.1142/S021849581850005X] C) [copyright World Scientific Publishing Company] [https://www.worldscientific.com/doi/abs/10.1142/S021849581850005X]

"I Want to Be Like You!": The Influence of Role Models on Entrepreneurial Intention

Katharina Fellnhofer (LUT School of Business and Management, Lappeenranta University of Technology, P. O. Box 20, 53851 Lappeenranta, Finland) and

Susan Mueller (Swiss Research Institute of Small Business and Entrepreneurship University of St. Gallen, Dufourstrasse 40a, 9000 St. Gallen, Switzerland)

that intentions are the best predictors of actual behavior (Armitage, and Conner 2001; Van Gelderen, Brand, van Praag, Bodewes, Poutsma, and Van Gils 2008). In this context, most studies applied the TPB (Fayolle, Gailly, and Lassas-Clerc 2006; Van Gelderen, Brand, van Praag, Bodewes, Poutsma, and Van Gils 2008; Kolvereid 1996b; Krueger, Reilly, and Carsrud 2000) or the EEM (Krueger 1993; Peterman, and Kennedy 2003).

Our work showed that role models can influence EIs, particularly via attitudes and desirability. This is especially important for educators who design entrepreneurship education programs aiming to increase students' propensity to start a company.

Gender differences. Referring to the role model effect, we assessed that gender has to be taken into careful consideration in this context. As is well known, the percentage of female entrepreneurs is lower than the percentage of male entrepreneurs (Kelley, Singer, and Herrington 2016). Overall, males tend to be more interested in an entrepreneurial career than females (Blanchflower, Oswald, and Stutzer 2001; Grilo, and Irigoyen 2006) and show a higher intention to start a business than females (Crant 1996; Minniti, and Nardone 2007; Wilson, Kickul, Marlino, Barbosa, and Griffiths 2009). In our study, we also detected significant gender differences. For instance, gender has a significant path to $\mathrm{PBC}(\mathrm{SRW}=-0.153, \mathrm{p}<.05)$ and $\mathrm{ESE}(\mathrm{SRW}=-0.177, \mathrm{p}<.05)$, meaning that females assess both their perceived behavioral control and ESE lower than their male counterparts. Furthermore, females tend to show significantly lower levels of perceived desirability and perceived feasibility than males. Consequently, the introduction of role models can be specifically important for women. 
Accepted Author Manuscript: Electronic version of an article published as Journal of Enterprising Culture 2018 26:02, 113-153 [https://doi.org/10.1142/S021849581850005X] C) [copyright World Scientific Publishing Company] [https://www.worldscientific.com/doi/abs/10.1142/S021849581850005X]

"I Want to Be Like You!": The Influence of Role Models on Entrepreneurial Intention

Katharina Fellnhofer (LUT School of Business and Management, Lappeenranta University of Technology, P. O. Box 20, 53851 Lappeenranta, Finland) and

Susan Mueller (Swiss Research Institute of Small Business and Entrepreneurship University of St. Gallen, Dufourstrasse 40a, 9000 St. Gallen, Switzerland)

Future research in this regard will contribute to an ongoing debate concerning individual gender-related perceptions and circumstances (Martin, McNally, and Kay 2013; Fellnhofer, Puumalainen, and Sjögrén 2016). A meta-analysis conducted by Martin et al. (2013) regarding the outcomes of entrepreneurship education recommends that future research should include gender as a potential moderator in entrepreneurship-related training, for instance. In this sphere, several authors stress that, in the case of entrepreneurship, sex matters significantly when it comes to perceptions (Powell, and Eddleston 2013).

Contribution toward behavior. As for conveying the realities of entrepreneurial life, Wood and Bandura (1989) postulate that entrepreneurial role models build beliefs in observers' abilities by passing on effective approaches for coping with different entrepreneurial situations. Entrepreneurial role models can thus increase PBC by strengthening one's perceptions of the necessary ability to cope with entrepreneurial challenges. Scholars such as BarNir et al. (2011) and Scherer et al. (1989) stress that entrepreneurial role models positively influence one's PBC. Our study supports this suggestion. Furthermore, Zellweger et al. (2011) emphasize that entrepreneurial role models positively enhance $\mathrm{PBC}$ and therefore promote the inclination to become an entrepreneur. Consequently, in line with Bandura (1997), our study contributes to this research stream by suggesting that entrepreneurial role models are anticipated to impact PBC as a mediating effect on EI.

We provide knowledge regarding the power of role models as stimulus for increasing EI. This clears the way for more theory-driven research in entrepreneurship education. So far, only a limited number of investigations have examined the different types of role models. 
Accepted Author Manuscript: Electronic version of an article published as Journal of Enterprising Culture 2018 26:02, 113-153 [https://doi.org/10.1142/S021849581850005X] C [copyright World Scientific Publishing Company] [https://www.worldscientific.com/doi/abs/10.1142/S021849581850005X]

"I Want to Be Like You!": The Influence of Role Models on Entrepreneurial Intention

Katharina Fellnhofer (LUT School of Business and Management, Lappeenranta University of Technology, P. O. Box 20, 53851 Lappeenranta, Finland) and

Susan Mueller (Swiss Research Institute of Small Business and Entrepreneurship University of St. Gallen, Dufourstrasse 40a, 9000 St. Gallen, Switzerland)

Exploring target group differences. We therefore recommend that scholars further examine which role models are specifically effective for which target groups. For example, how do characteristics of the role model such as gender, culture, experience, and other relevant factors influence the power of role models as influencers and career-boosters? In this regard, it is also crucial to inspect the differing influence of successful and failed entrepreneurial role models. It could be, for example, that stories of failure are more effective since these stories convey why an entrepreneurial endeavor failed, whereas it is not always clear why a successful start-up was successful. Knowledge of why something does not work, so-called "negative knowledge" (Oser, and Spychiger 2005), is an important element in learning.

The different functions of role models. Another aspect that needs to be considered in more depth is related to the different functions of role models. Bosma et al. (2012) found that role models mainly had the following functions for nascent entrepreneurs: "learning by example," "learning by support," "increasing entrepreneurial self-efficacy," and "inspiration/moderation." For entrepreneurship educators, it would be relevant to understand how these different functions can be elicited (e.g. through which type of role models and which pedagogical approaches).

Role models and media. Additionally, researchers could take advantage of today's innovationdriven media for entrepreneurship education. Children are digital natives demanding state-of-theart communication channels and teaching and learning aids. Consequently, there are open research questions regarding which channels are most effective for future entrepreneurs. Are short, eyecatching multimedia videos on social media more effective than intensive live talks in class? How do we assess long-term effects in this regard? The answers to these research questions might also 
Accepted Author Manuscript: Electronic version of an article published as Journal of Enterprising Culture 2018 26:02, 113-153 [https://doi.org/10.1142/S021849581850005X] C [copyright World Scientific Publishing Company] [https://www.worldscientific.com/doi/abs/10.1142/S021849581850005X]

"I Want to Be Like You!": The Influence of Role Models on Entrepreneurial Intention

Katharina Fellnhofer (LUT School of Business and Management, Lappeenranta University of Technology, P. O. Box 20, 53851 Lappeenranta, Finland) and

Susan Mueller (Swiss Research Institute of Small Business and Entrepreneurship University of St. Gallen, Dufourstrasse 40a, 9000 St. Gallen, Switzerland)

be crucial for policy-makers when creating an entrepreneurial culture in different regions. As culture affects the impact of different role model types applied in entrepreneurship education, it might be also worth performing further global, cross-cultural studies.

Next, our results highlight that age plays a role. Role models tend to affect different generations differently, meaning that potential entrepreneurs in kindergarten have to be made aware in a different manner to potential entrepreneurs in pre-school, high school or college. How to approach different age groups most effectively via role models is still an open question. Furthermore, we anticipate positive side effects of role models not only for entrepreneurs, but also for employees — effects which are largely unexplored thus far. Nevertheless, we do not want to claim that role models are a panacea for entrepreneurship education. But they can play a strong role and show high potential when it comes to supporting pedagogies effectively in entrepreneurship education.

\section{Limitations}

As with any other investigation, our study faces limitations. One central restriction of this work is its dependent variable, namely EI and its relation to actual entrepreneurial behavior. Using the construct of EI as a dependent variable imposes a limitation related to the validity and persistence of the relationship between perceived and actual behavior, which can only be assessed using a longitudinal approach (Davidsson, and Honig 2003). Nevertheless, as discussed in the meta-analytic review of Armitage and Conner (2001), previous research identifies the TPB as the best predictor of planned behavior across a diverse range of disciplines. As supported by meta-analytic evidence, the variance explained by EI in actual entrepreneurial behavior ranges between $30 \%$ and 40\% (Armitage, and Conner 2001; Schlaegel, and Koenig 2013). However, the strength of the 
Accepted Author Manuscript: Electronic version of an article published as Journal of Enterprising Culture 2018 26:02, 113-153 [https://doi.org/10.1142/S021849581850005X] C) [copyright World Scientific Publishing Company] [https://www.worldscientific.com/doi/abs/10.1142/S021849581850005X]

"I Want to Be Like You!": The Influence of Role Models on Entrepreneurial Intention

Katharina Fellnhofer (LUT School of Business and Management, Lappeenranta University of Technology, P. O. Box 20, 53851 Lappeenranta, Finland) and

Susan Mueller (Swiss Research Institute of Small Business and Entrepreneurship University of St. Gallen, Dufourstrasse 40a, 9000 St. Gallen, Switzerland)

intention-behavior link in entrepreneurship has been questioned (Katz 1990; Bird 1992; Katz 1992). Next, as discussed in the methodology section in Table 7 regarding goodness-of-fit indices, the models show robustness, validity, and reliability in terms of prior research (e.g., Kolvereid 1996a; Krueger 2009; Liñán, and Chen 2009). Accordingly, future research needs to include actual behavior to investigate further the power of the intent-behavior relationship, particularly taking into account role models in entrepreneurship research.

Additionally, the ongoing discussion in the literature stream dedicated to entrepreneurial role models lacks comprehensive impact studies by means of a pre-post-post design. Analyzing the (in)direct effects of entrepreneurial role models on individuals taking both the short- and long term into account would not only enrich the academic dialogue in entrepreneurship education, but also widen practitioners' ecosphere with further evidence of the significant positive forces and vigorous leverages of entrepreneurial role models on nascent entrepreneurs.

The limited geographical scope of this study is an additional weakness. Our study's sample primarily comprises individuals from Austria, Finland, and Greece. Consequently, as our results indicate, national background impacts several levels of perception, which should be treated with caution when analyzing our data. Finally, the generalization of our results is restricted in this respect.

Furthermore, we focused on established concepts when analyzing the direct effects of different paths. We did not test mediation effects via the Sobel test. As a result, this work could be extended in this context to provide further in-depth insights of different direct and indirect effects to analyze the mediators of the constructs in more detail. 
Accepted Author Manuscript: Electronic version of an article published as Journal of Enterprising Culture 2018 26:02, 113-153 [https://doi.org/10.1142/S021849581850005X] C) [copyright World Scientific Publishing Company] [https://www.worldscientific.com/doi/abs/10.1142/S021849581850005X]

"I Want to Be Like You!": The Influence of Role Models on Entrepreneurial Intention

Katharina Fellnhofer (LUT School of Business and Management, Lappeenranta University of Technology, P. O. Box 20, 53851 Lappeenranta, Finland) and

Susan Mueller (Swiss Research Institute of Small Business and Entrepreneurship University of St. Gallen, Dufourstrasse 40a, 9000 St. Gallen, Switzerland) 
Accepted Author Manuscript: Electronic version of an article published as Journal of Enterprising Culture 2018 26:02, 113-153 [https://doi.org/10.1142/S021849581850005X] C) [copyright World Scientific Publishing Company] [https://www.worldscientific.com/doi/abs/10.1142/S021849581850005X]

"I Want to Be Like You!": The Influence of Role Models on Entrepreneurial Intention

Katharina Fellnhofer (LUT School of Business and Management, Lappeenranta University of Technology, P. O. Box 20, 53851 Lappeenranta, Finland) and

Susan Mueller (Swiss Research Institute of Small Business and Entrepreneurship University of St. Gallen, Dufourstrasse 40a, 9000 St. Gallen, Switzerland)

\section{References}

Gibson, Donald E (2004). "Role Models in Career Development: New Directions for Theory and Research," Journal Of Vocational Behavior 65(1), 134-156.

Kolvereid, Lars (1996a). "Prediction of Employment Status Choice Intentions," in Working Paper Series. Henley: Henley Management College HWP.

Krueger, Norris F, Reilly, Michael D and Carsrud, Alan L (2000). "Competing Models of Entrepreneurial Intentions," Journal Of Business Venturing 15(5), 411-432.

Tegtmeier, Silke (2006). "Explaining Individual Entrepreneurial Intentions: The Theory of Planned Behavior as a Social-Psychological Model in the Context of Entrepreneurship," Neuropsychoeconomics Conference Proceedings 1(1), 22-22.

Schlaegel, C. and Koenig, M. (2013). "Determinants of Entrepreneurial Intent: A Meta-Analytic Test and Integration of Competing Models," Entrepreneurship: Theory \& Practice 38(2), 291-332.

BarNir, Anat, Watson, Warren E and Hutchins, Holly M (2011). "Mediation and Moderated Mediation in the Relationship among Role Models, Self-Efficacy, Entrepreneurial Career Intention, and Gender," Journal Of Applied Social Psychology 41(2), 270-297.

Scherer, Robert F, Adams, Janet S, Carley, Susan and Wiebe, Frank A (1989). "Role Model Performance Effects on Development of Entrepreneurial Career Preference," Entrepreneurship: Theory \& Practice 13(3), $53-71$.

Rosique-Blasco, Mario, Madrid-Guijarro, Antonia and García-Pérez-de-Lema, Domingo (2016). "Entrepreneurial Skills and Socio-Cultural Factors," Education + Training 58(7/8), 815-831.

Kim, Min-Sun and Hunter, John E (1993). "Relationships among Attitudes, Behavioral Intentions, and Behavior: A Meta-Analysis of Past Research, Part 2," Communication research 20(3), 331-364.

Kautonen, Teemu, Gelderen, Marco and Fink, Matthias (2013). "Robustness of the Theory of Planned Behavior in Predicting Entrepreneurial Intentions and Actions," Entrepreneurship: Theory \& Practice 39(3), 655-674.

Muller, Patrice, Devnani, Shaan , Julius, Jenna, Gagliardi, Dimitri and Marzocchi, Chiara (2016). "Sme Recovery Continues," in ANNUAL REPORT ON EUROPEAN SMES 2015/2016. . Ed. K. Hope. European Commission - Brussels: CARSA, PwC Luxembourg, London Economics, Innova, The University of Manchester, Manchester Institute of Innovation Research, DIW Berlin, DIW Econ.

Eurostat (2017). "Statistics About Smes in Europe." Brussels: European Parliament, Eurostat.

Bird, Miriam, Halter, Frank A, Zellweger, Thomas Markus, Kissling Streuli, Sonja, Andric, Mateja, Christen, Andreas, Gachet, Emilie and Schenk, Roman (2016). "Company Succession in Practice-the Challenge of Generation Change. Arbeitsbericht.." Zürich: Credit Suisse. Economic Research.

Williams, Colin C., Martinez-Perez, Alvaro and Kedir, Abbi M. (2017). "Informal Entrepreneurship in Developing Economies: The Impacts of Starting up Unregistered on Firm Performance," Entrepreneurship: Theory \& Practice 41(5), 773-799.

Schneider, F and Williams, CC (2013). "The Shadow Economy." London: Institute of Economic Affairs.

Jütting, Johannes and de Laiglesia, Juan R (2009). Employment, Poverty Reduction and Development: What's New? Paris: Development Centre of the Organisation for Economic Co-operation and Development (OECD).

ILO (2013). http://www.ilo.org/ilostat/faces/wcnav defaultSelection;ILOSTATCOOKIE $=$ W1X7rp6cocmddfvtsATotXSCmGhOhnkmOkOO9n7NJ6DCQJVmQZN!2042799778 ? afrLoop $=715996640281479 \&$ afrWindowMode $=0 \&$ afrWindowId $=$ null $\# ! \% 40 \% 40 \% 3$ F afrWindowId\%3Dnull\%26 afrLoop\%3D715996640281479\%26 afrWindowMode\%3D0\%26 adf.c trl-state\%3Dftk8smsd 4 (06.09.2017) 
Accepted Author Manuscript: Electronic version of an article published as Journal of Enterprising Culture 2018 26:02, 113-153 [https://doi.org/10.1142/S021849581850005X] C) [copyright World Scientific Publishing Company] [https://www.worldscientific.com/doi/abs/10.1142/S021849581850005X]

"I Want to Be Like You!": The Influence of Role Models on Entrepreneurial Intention

Katharina Fellnhofer (LUT School of Business and Management, Lappeenranta University of Technology, P. O. Box 20, 53851 Lappeenranta, Finland) and

Susan Mueller (Swiss Research Institute of Small Business and Entrepreneurship University of St. Gallen, Dufourstrasse 40a, 9000 St. Gallen, Switzerland)

Ajzen, Icek (1991). "The Theory of Planned Behavior," Organizational Behavior And Human Decision Processes 50(2), 179-211.

Shapero, Albert and Sokol, Lisa (1982). "The Social Dimensions of Entrepreneurship," in Encyclopedia of Entrepreneurship. Eds. C. A. Kent, D. L. Sexton and K. H. Vesper. New York: Englewood Cliffs, NJ: Prentice-Hall, 72-90.

Bird, B. (1988). "Implementing Entrepreneurial Ideas: The Case for Intention," Academy Of Management Review 13(3), 442-453.

Hashim, H. A., Jawis, M. N., Wahat, A. and Grove, J. R. (2014). "Children's Exercise Behavior: The Moderating Role of Habit Processes within the Theory of Planned Behavior," Psychology, Health \& Medicine 19(3), 335-343.

Williamson, Linzi E. A. and Lawson, Karen L. (2015). "Young Women's Intentions to Delay Childbearing: A Test of the Theory of Planned Behaviour," Journal of Reproductive \& Infant Psychology 33(2), 205213.

Lheureux, Florent, Auzoult, Laurent, Charlois, Colette, Hardy-Massard, Sandrine and Minary, Jean-Pierre (2016). "Traffic Offences: Planned or Habitual? Using the Theory of Planned Behaviour and Habit Strength to Explain Frequency and Magnitude of Speeding and Driving under the Influence of Alcohol," British Journal of Psychology 107(1), 52-71.

Sagas, Michael, Cunningham, George and Pastore, Donna (2006). "Predicting Head Coaching Intentions of Male and Female Assistant Coaches: An Application of the Theory of Planned Behavior," Sex Roles 54(9-10), 695-705.

Hamilton, Kyra, Cox, Stephen and White, Katherine M. (2012). "Testing a Model of Physical Activity among Mothers and Fathers of Young Children: Integrating Self-Determined Motivation, Planning, and the Theory of Planned Behavior," Journal of Sport \& Exercise Psychology 34(1), 124-145.

Agarwal, Vinita (2014). "A/H1n1 Vaccine Intentions in College Students: An Application of the Theory of Planned Behavior," Journal of American College Health 62(6), 416-424.

Catalano, Hannah Priest, Knowlden, Adam P., Birch, David A., Leeper, James D., Paschal, Angelia M. and Usdan, Stuart L. (2017). "Using the Theory of Planned Behavior to Predict Hpv Vaccination Intentions of College Men," Journal of American College Health 65(3), 197-207.

Krueger Jr, Norris F (2017). "Chapter 2: Entrepreneurial Intentions Are Dead: Long Live Entrepreneurial Intentions," in Revisiting the Entrepreneurial Mind inside the Black Box: An Expanded Edition, International Studies in Entrepreneurship. Eds. M. Brännback and A. L. Carsrud. Switzerland: Springer.

Ajzen, Icek (2002). "Perceived Behavioral Control, Self-Efficacy, Locus of Control, and the Theory of Planned Behavior," Journal of applied social psychology 32(4), 665-683.

Byabashaija, Warren and Katono, Isaac (2011). "The Impact of College Entrepreneurial Education on Entrepreneurial Attitudes and Intention to Start a Business in Uganda," Journal of Developmental Entrepreneurship 16(01), 127-144.

Lucas, William A and Cooper, SY (2012). "Theories of Entrepreneurial Intention and the Role of Necessity," in Proceedings of the 35th Institute of Small Business and Entrepreneurship Conference 2012.

Shook, Christopher L and Bratianu, Constantin (2010). "Entrepreneurial Intent in a Transitional Economy: An Application of the Theory of Planned Behavior to Romanian Students," International Entrepreneurship and Management Journal 6(3), 231-247.

Carr, Jon C and Sequeira, Jennifer M (2007). "Prior Family Business Exposure as Intergenerational Influence and Entrepreneurial Intent: A Theory of Planned Behavior Approach," Journal Of Business Research 60(10), 1090-1098. 
Accepted Author Manuscript: Electronic version of an article published as Journal of Enterprising Culture 2018 26:02, 113-153 [https://doi.org/10.1142/S021849581850005X] C) [copyright World Scientific Publishing Company] [https://www.worldscientific.com/doi/abs/10.1142/S021849581850005X]

"I Want to Be Like You!": The Influence of Role Models on Entrepreneurial Intention

Katharina Fellnhofer (LUT School of Business and Management, Lappeenranta University of Technology, P. O. Box 20, 53851 Lappeenranta, Finland) and

Susan Mueller (Swiss Research Institute of Small Business and Entrepreneurship University of St. Gallen, Dufourstrasse 40a, 9000 St. Gallen, Switzerland)

Engle, R. L. , Dimitriadi, N. , Gavidia, Jose V., Schlaegel, Christopher , Delanoe, Servane , Alvarado, Irene , He, Xiaohong , Buame, Samuel and Wolff, Birgitta (2010). "Entrepreneurial Intent a TwelveCountry Evaluation of Ajzen's Model of Planned Behavior," International Journal Of Entrepreneurial Behaviour \& Research 16(1), 35-57.

Kolvereid, Lars and Isaksen, Espen (2006). "New Business Start-up and Subsequent Entry into SelfEmployment," Journal Of Business Venturing 21(6), 866-885.

Liñán, Francisco and Santos, Francisco Javier (2007). "Does Social Capital Affect Entrepreneurial Intentions?," International Advances in Economic Research 13(4), 443-453.

Krueger, Norris F and Carsrud, Alan L (1993). "Entrepreneurial Intentions: Applying the Theory of Planned Behaviour," Entrepreneurship \& Regional Development 5(4), 315-330.

Zellweger, Thomas, Sieger, Philipp and Halter, Frank (2011). "Should I Stay or Should I Go? Career Choice Intentions of Students with Family Business Background," Journal Of Business Venturing 26(5), 521 536.

Bandura, Albert (1997). Self-Efficacy: The Exercise of Control: Macmillan.

Heuer, Annamária and Liñán, Francisco (2013). "Testing Alternative Measures of Subjective Norms in Entrepreneurial Intention Models," International Journal of Entrepreneurship and Small Business 19(1), 35-50.

Van Auken, Howard, Fry, Fred L and Stephens, Paul (2006). "The Influence of Role Models on Entrepreneurial Intentions," Journal Of Developmental Entrepreneurship 11(02), 157-167.

Kolvereid, Lars (1996b). "Prediction of Employment Status Choice Intentions," Entrepreneurship: Theory \& Practice 21(1), 47-58.

Scherer, Robert F, Brodzinski, James D and Wiebe, Franka (1991). "Examining the Relationship between Personality and Entrepreneurial Career Preference 1," Entrepreneurship \& Regional Development 3(2), 195-206.

Krueger, N. (1993). "The Impact of Prior Entrepreneurial Exposure on Perceptions of New Venture Feasibility and Desirability," Entrepreneurship: Theory \& Practice 18(1), 5-21.

Nauta, Margaret M and Kokaly, Michelle L (2001). "Assessing Role Model Influences on Students' Academic and Vocational Decisions," Journal Of Career Assessment 9(1), 81-99.

Bandura, Albert (1986). Social Foundations of Thought and Action: A Social Cognitive Theory. NJ: Englewood Cliffs, Prentice-Hall.

Liñán, Francisco and Chen, Yi-Wen (2009). "Development and Cross-Cultural Application of a Specific Instrument to Measure Entrepreneurial Intentions," Entrepreneurship: Theory \& Practice 33(3), 593617.

Chen, Gilad, Gully, Stanley M and Eden, Dov (2001). "Validation of a New General Self-Efficacy Scale," Organizational Research Methods 4(1), 62-83.

Kickul, Jill, Gundry, Lisa K, Barbosa, Saulo D and Whitcanack, Laney (2009). "Intuition Versus Analysis? Testing Differential Models of Cognitive Style on Entrepreneurial Self-Efficacy and the New Venture Creation Process," Entrepreneurship: Theory \& Practice 33(2), 439-453.

Peterman, Nicole E. and Kennedy, Jessica (2003). "Enterprise Education: Influencing Students' Perceptions of Entrepreneurship," Entrepreneurship: Theory \& Practice 28(2), 129-144.

Nunnally, J. (1978). Psychometric Theory. New York: McGraw-Hill.

Hair, Josefph F, Anderson, Rolph E, Tatham, Ronald L and Black, William C (1995). Multivariate Data Analyses with Readings. NJ: Prentice Hall College Div.

Loewenthal, K. M. (2004). An Introduction to Psychological Tests and Scales (2 Ed.). Hove, UK: Psychology Press. 
Accepted Author Manuscript: Electronic version of an article published as Journal of Enterprising Culture 2018 26:02, 113-153 [https://doi.org/10.1142/S021849581850005X] C) [copyright World Scientific Publishing Company] [https://www.worldscientific.com/doi/abs/10.1142/S021849581850005X]

"I Want to Be Like You!": The Influence of Role Models on Entrepreneurial Intention

Katharina Fellnhofer (LUT School of Business and Management, Lappeenranta University of Technology, P. O. Box 20, 53851 Lappeenranta, Finland) and

Susan Mueller (Swiss Research Institute of Small Business and Entrepreneurship University of St. Gallen, Dufourstrasse 40a, 9000 St. Gallen, Switzerland)

Levesque, Moren and Minniti, Maria (2006). "The Effect of Aging on Entrepreneurial Behavior," Journal Of Business Venturing 21(2), 177-194.

Brush, Candida G (1992). "Research on Women Business Owners: Past Trends, a New Perspective and Future Directions," Entrepreneurship: Theory \& Practice 16(4), 5-31.

Herrington, M. and Kew, P. (2017). Global Entrepreneurship Monitor. Global Report 2016/2017. Babson: Babson Park.

Shinnar, Rachel S., Hsu, Dan K. and Powell, Benjamin C. (2014). "Self-Efficacy, Entrepreneurial Intentions, and Gender: Assessing the Impact of Entrepreneurship Education Longitudinally," The International Journal Of Management Education 12(3), 561-570.

Kelley, Donna, Singer, Slavica and Herrington, Mike (2016). "2015/16 Global Report - Gem Global Entrepreneurship Monitor." Ed. G. E. R. A. (GERA). Babson Park, MA, United States; Santiago, Chile; Malaysia; Mexiko; London, United Kingdom: Babson College, Universidad del Desarrollo, Universiti Tun Abdul Razak, Tecnológico de Monterrey, London Business School.

Fellnhofer, K., Puumalainen, K. and Sjögrén, H. (2016). "Entrepreneurial Orientation and Performance Are Sexes Equal?," International Journal Of Entrepreneurial Behavior \& Research 22(3), 346-374.

Unger, Jens M, Rauch, Andreas, Frese, Michael and Rosenbusch, Nina (2011). "Human Capital and Entrepreneurial Success: A Meta-Analytical Review," Journal Of Business Venturing 26(3), 341-358.

Arenius, Pia and Minniti, Maria (2005). "Perceptual Variables and Nascent Entrepreneurship," Small Business Economics 24(3), 233-247.

Wagner, Joachim and Sternberg, Rolf (2004). "Start-up Activities, Individual Characteristics, and the Regional Milieu: Lessons for Entrepreneurship Support Policies from German Micro Data," The Annals Of Regional Science 38(2), 219-240.

Zampetakis, Leonidas A, Lerakis, Manolis, Kafetsios, Konstantinos and Moustakis, Vassilis (2015). "Investigating the Emotional Impact of Entrepreneurship Programs," Journal Of Business Venturing Insights 4, 38-41.

Anderson, D. R., Sweeney, D. J. and T.A., Williams (2002). Statistics for Business and Economics. Singapore: Thomson Asia Pte Ltd.

Allison, PD (1999). Multicollinearity in Logistic Regression. Cary, NC: SAS Institute.

Viswesvaran, Chockalingam and Ones, Deniz S (1995). "Theory Testing: Combining Psychometric MetaAnalysis and Structural Equations Modeling," Personnel psychology 48(4), 865-885.

Hedges, Larry V (2009). "Statistical Considerations," The Handbook of Research Synthesis and MetaAnalysis, 38-47.

Leavitt, Keith, Mitchell, Terence R and Peterson, Jeff (2010). "Theory Pruning: Strategies to Reduce Our Dense Theoretical Landscape," Organizational Research Methods 13(4), 644-667.

Hair Jr, JF, Black, WC, Babin, BJ, Anderson, RE and Tatham, RL (2010). "Sem: An Introduction," Multivariate data analysis: A global perspective, 629-686.

Kline, Rex B (2005). "Principles and Practice of Structural Equation Modeling, 2e Éd., New York," Guilford Press.

Armitage, Christopher J and Conner, Mark (2001). "Efficacy of the Theory of Planned Behaviour: A MetaAnalytic Review," British Journal Of Social Psychology 40(4), 471-499.

Conner, Mark and Armitage, Christopher J (1998). "Extending the Theory of Planned Behavior: A Review and Avenues for Further Research," Journal of applied social psychology 28(15), 1429-1464.

Notani, Arti Sahni (1998). "Moderators of Perceived Behavioral Control's Predictiveness in the Theory of Planned Behavior: A Meta-Analysis," Journal of consumer psychology 7(3), 247-271.

Fornell, Claes and Larcker, David F (1981). "Structural Equation Models with Unobservable Variables and Measurement Error: Algebra and Statistics," Journal of marketing research 18(3), 382-388. 
Accepted Author Manuscript: Electronic version of an article published as Journal of Enterprising Culture 2018 26:02, 113-153 [https://doi.org/10.1142/S021849581850005X] C) [copyright World Scientific Publishing Company] [https://www.worldscientific.com/doi/abs/10.1142/S021849581850005X]

"I Want to Be Like You!": The Influence of Role Models on Entrepreneurial Intention

Katharina Fellnhofer (LUT School of Business and Management, Lappeenranta University of Technology, P. O. Box 20, 53851 Lappeenranta, Finland) and

Susan Mueller (Swiss Research Institute of Small Business and Entrepreneurship University of St. Gallen, Dufourstrasse 40a, 9000 St. Gallen, Switzerland)

Janssens, W., Wijnen, K., Depelsmacker, P. and van Kenhone, P. (2008). Marketing Research with Spss. England: Prentice Hall-FT.

Nunnally, Jum C and Bernstein, IH (1994). Psychological Theory. New York: McGraw-Hill.

Podsakoff, P.M., MacKenzie, S.B., Lee, J.-Y. and Podsakoff, N.P. (2003). "Common Method Biases in Behavioral Research: A Critical Review of the Literature and Recommended Remedies," Journal Of Applied Psychology 88(5), 879-903.

Cooper, Harris, Hedges, Larry V and Valentine, Jeffrey C (2009). The Handbook of Research Synthesis and Meta-Analysis: Russell Sage Foundation.

Elfving, Jennie, Brännback, Malin and Carsrud, Alan (2009). "Toward a Contextual Model of Entrepreneurial Intentions," in Understanding the Entrepreneurial Mind. Heidelberg: Springer, 23-33.

--- (2017). "Toward a Contextual Model of Entrepreneurial Intentions," in Revisiting the Entrepreneurial Mind. Heidelberg: Springer, 71-81.

Lin, Xiaohua, Carsrud, Alan, Jagoda, Kalinga and Shen, Wanqing (2013). "Determinants of Entrepreneurial Intentions: Applying Western Model to the Sri Lanka Context," Journal of Enterprising Culture 21(02), 153-174.

Krueger, N. and Brazeal, P. (1994). "Entrepreneurial Potential \& Potential Entrepreneurs," Entrepreneurship: Theory \& Practice 18(3), 91-104.

McGrath, Rita Gunther and MacMillan, Ian C (1992). "More Like Each Other Than Anyone Else? A CrossCultural Study of Entrepreneurial Perceptions," Journal of Business Venturing 7(5), 419-429.

Davidsson, Per and Wiklund, Johan (1997). "Values, Beliefs and Regional Variations in New Firm Formation Rates," Journal of Economic psychology 18(2), 179-199.

Krueger, N and Kickul, J (2006). "So You Thought the Intentions Model Was Simple," in Navigating the complexities \& interactions of cognitive style, culture, gender, social norms, \& intensity on the pathways to entrepreneurship, USASBE conference, Tuscon, AZ.

Chlosta, S., Patzelt, H., Klein, S. B. and Dormann, C. (2012). "Parental Role Models and the Decision to Become Self-Employed: The Moderating Effect of Personality," Small Business Economics 38(1), 121 138.

Franco, Mário, Haase, Heiko and Lautenschläger, Arndt (2010). "Students' Entrepreneurial Intentions: An Inter-Regional Comparison," Education+ Training 52(4), 260-275.

Hoang, Ha and Gimeno, Javier (2010). "Becoming a Founder: How Founder Role Identity Affects Entrepreneurial Transitions and Persistence in Founding," Journal Of Business Venturing 25(1), 41-53.

Phillips, Nelson, Tracey, Paul and Karra, Neri (2013). "Building Entrepreneurial Tie Portfolios through Strategic Homophily: The Role of Narrative Identity Work in Venture Creation and Early Growth," Journal Of Business Venturing 28(1), 134-150.

Donnellon, Anne, Ollila, Susanne and Middleton, Karen Williams (2014). "Constructing Entrepreneurial Identity in Entrepreneurship Education," The International Journal Of Management Education 12(3), 490-499.

Pittaway, Luke and Cope, Jason (2007). "Entrepreneurship Education: A Systematic Review of the Evidence," International Small Business Journal 25(5), 479-510.

Albornoz, Carlos A. (2008). "Toward a Set of Trainable Content on Entrepreneurship Education: A Review of Entrepreneurship Research from an Educational Perspective," Journal Of Technology Management \& Innovation 3(2), 86-98.

Rasmussen, Einar (2011). "Book Review: Entrepreneurship Education," International Small Business Journal 29(6), 731-733.

Lorz, Michael, Mueller, Susan and Volery, Thierry (2013). "Entrepreneurship Education: A Systematic Review of the Methods in Impact Studies," Journal Of Enterprising Culture 21(2), 123-151. 
Accepted Author Manuscript: Electronic version of an article published as Journal of Enterprising Culture 2018 26:02, 113-153 [https://doi.org/10.1142/S021849581850005X] C [copyright World Scientific Publishing Company] [https://www.worldscientific.com/doi/abs/10.1142/S021849581850005X]

"I Want to Be Like You!": The Influence of Role Models on Entrepreneurial Intention

Katharina Fellnhofer (LUT School of Business and Management, Lappeenranta University of Technology, P. O. Box 20, 53851 Lappeenranta, Finland) and

Susan Mueller (Swiss Research Institute of Small Business and Entrepreneurship University of St. Gallen, Dufourstrasse 40a, 9000 St. Gallen, Switzerland)

Van Gelderen, Marco, Brand, Maryse, van Praag, Mirjam, Bodewes, Wynand, Poutsma, Erik and Van Gils, Anita (2008). "Explaining Entrepreneurial Intentions by Means of the Theory of Planned Behaviour," Career Development International 13(6), 538-559.

Fayolle, Alain, Gailly, Benoît and Lassas-Clerc, Narjisse (2006). "Assessing the Impact of Entrepreneurship Education Programmes: A New Methodology," Journal Of European Industrial Training 30(8/9), 701-720.

Blanchflower, D.G., Oswald, A. and Stutzer, A. (2001). "Latent Entrepreneurship across Nations," European Economic Review 45(4-6), 680-691.

Grilo, I. and Irigoyen, J. M. (2006). "Entrepreneurship in the Eu: To Wish and Not to Be," Small Business Economics 26(4), 305-318.

Crant, J. M. (1996). "The Proactive Personality Scale as a Predictor of Entrepreneurial Intentions," Journal Of Small Business Management 34(3), 42-49.

Minniti, Maria and Nardone, Carlo (2007). "Being in Someone Else's Shoes: The Role of Gender in Nascent Entrepreneurship," Small Business Economics 28(2), 223-238.

Wilson, Fiona, Kickul, Jill, Marlino, Deborah, Barbosa, Saulo D and Griffiths, Mark D (2009). "An Analysis of the Role of Gender and Self-Efficacy in Developing Female Entrepreneurial Interest and Behavior," Journal of developmental Entrepreneurship 14(02), 105-119.

Martin, B. C., McNally, J. J. and Kay, M. J. (2013). "Examining the Formation of Human Capital in Entrepreneurship: A Meta-Analysis of Entrepreneurship Education Outcomes," Journal Of Business Venturing 28(2), 211-224.

Powell, Gary N. and Eddleston, Kimberly A. (2013). "Linking Family-to-Business Enrichment and Support to Entrepreneurial Success: Do Female and Male Entrepreneurs Experience Different Outcomes?," Journal Of Business Venturing 28(2), 261-280.

Wood, R. and Bandura, A. (1989). "Social Cognitive Theory of Organizational Management," Academy Of Management Review 14, 361-384.

Oser, Fritz and Spychiger, Maria (2005). Lernen Ist Schmerzhaft: Zur Theorie Des Negativen Wissens Und Zur Praxis Der Fehlerkultur. Weinheim: Beltz.

Bosma, Niels, Hessels, Jolanda, Schutjens, Veronique, Van Praag, Mirjam and Verheul, Ingrid (2012). "Entrepreneurship and Role Models," Journal Of Economic Psychology 33(2), 410-424.

Davidsson, P. and Honig, B. (2003). "The Role of Social and Human Capital among Nascent Entrepreneurs," Journal Of Business Venturing 18(1), 301-331.

Katz, Jerome A (1990). "Longitudinal Analysis of Self-Employment Follow-Through," Entrepreneurship \& Regional Development 2(1), 15-26.

Bird, Barbara J (1992). "The Operation of Intentions in Time: The Emergence of the New Venture," Entrepreneurship: Theory \& Practice 17(1), 11-21.

Katz, Jerome A (1992). "Modelling Entrepreneurial Career Progressions: Concepts and Considerations," Entrepreneurship: Theory \& Practice 19(2), 23-40.

Krueger, Norris F (2009). "The Microfoundations of Entrepreneurial Learning and... Education: The Experiential Essence of Entrepreneurial Cognition," in Handbook of University-Wide Entrepreneurship Education. Ed. E. J. G. K. G. S. G. P. West. NJ: Edward Elgar, 35-59.

Bagozzi, R. P., Yi, Y. (1988). "On the Evaluation of Structural Equation Models," Journal Of The Academy Of Marketing Science 16(1), 74-94.

Raykov, Tenko (1997). "Estimation of Composite Reliability for Congeneric Measures," Applied Psychological Measurement 21(2), 173-184.

Kaiser, Henry F (1974). "An Index of Factorial Simplicity," Psychometrika 39(1), 31-36. 
Accepted Author Manuscript: Electronic version of an article published as Journal of Enterprising Culture 2018 26:02, 113-153 [https://doi.org/10.1142/S021849581850005X] C [copyright World Scientific Publishing Company] [https://www.worldscientific.com/doi/abs/10.1142/S021849581850005X]

"I Want to Be Like You!": The Influence of Role Models on Entrepreneurial Intention

Katharina Fellnhofer (LUT School of Business and Management, Lappeenranta University of Technology, P. O. Box 20, 53851 Lappeenranta, Finland) and

Susan Mueller (Swiss Research Institute of Small Business and Entrepreneurship University of St. Gallen, Dufourstrasse 40a, 9000 St. Gallen, Switzerland)

Bartlett, Maurice (1937). "Properties of Sufficiency and Statistical Tests," Proceedings Of The Royal Statistical Society Series A 160, 268-282. 
Accepted Author Manuscript: Electronic version of an article published as Journal of Enterprising Culture 2018 26:02, 113-153 [https://doi.org/10.1142/S021849581850005X] C [copyright World Scientific Publishing Company] [https://www.worldscientific.com/doi/abs/10.1142/S021849581850005X]

"I Want to Be Like You!": The Influence of Role Models on Entrepreneurial Intention

Katharina Fellnhofer (LUT School of Business and Management, Lappeenranta University of Technology, P. O. Box 20, 53851 Lappeenranta, Finland) and

Susan Mueller (Swiss Research Institute of Small Business and Entrepreneurship University of St. Gallen, Dufourstrasse 40a, 9000 St. Gallen, Switzerland)

Figure 1. Role models' influence on entrepreneurial intention

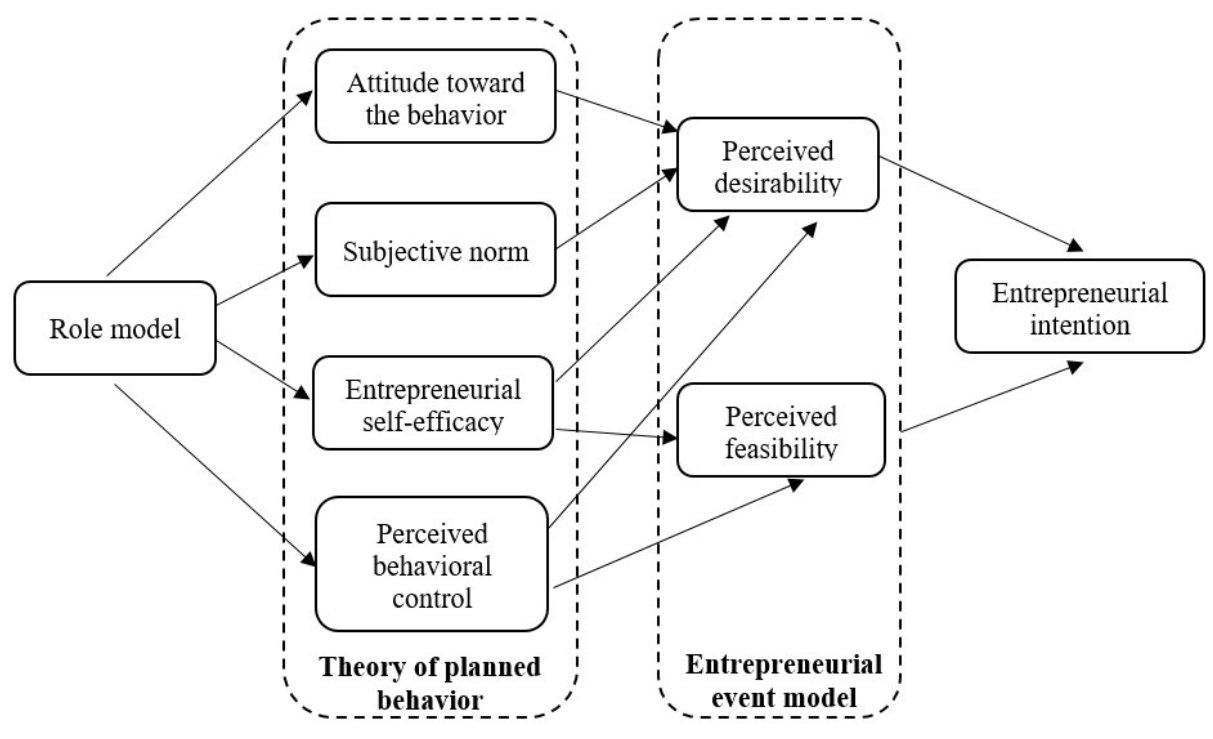

Figure 2. Results of role models' influence on entrepreneurial intention

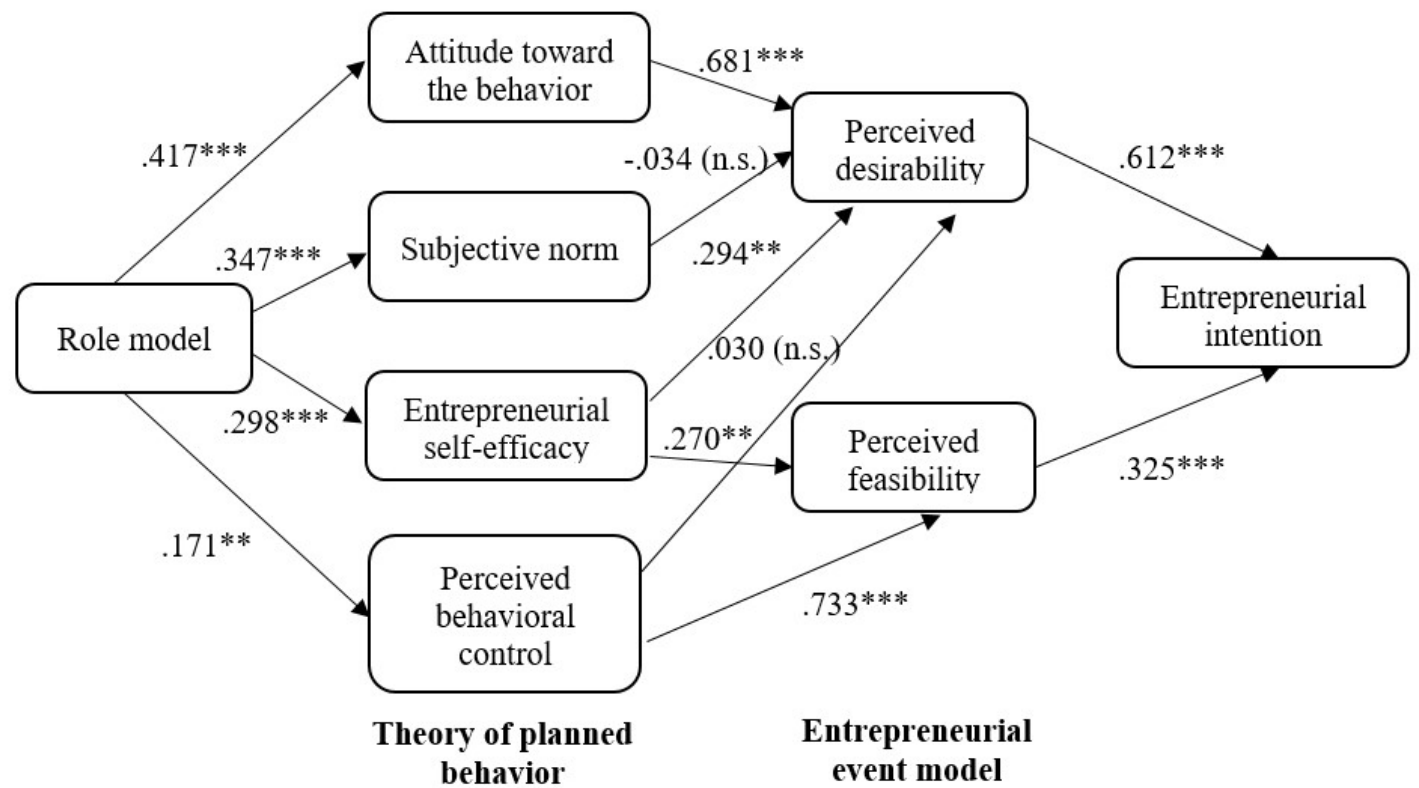

Note: $\chi 2=1804,799 ; \chi^{2} / \mathrm{df}=1.65 ; \mathrm{GFI}=0.792 ; \mathrm{CFI}=0.893 ; \mathrm{TLI}=0.881 ; \mathrm{IFI}=0.895 ; \mathrm{RMSEA}=0.050$. Standardized regression weights (SRW) are marked as follows $\dagger p<.10 ;{ }^{*} p<.05 ; * * p<.01 ; * * * p<.001$. 
Accepted Author Manuscript: Electronic version of an article published as Journal of Enterprising Culture 2018 26:02, 113-153 [https://doi.org/10.1142/S021849581850005X] C) [copyright World Scientific Publishing Company] [https://www.worldscientific.com/doi/abs/10.1142/S021849581850005X]

"I Want to Be Like You!": The Influence of Role Models on Entrepreneurial Intention

Katharina Fellnhofer (LUT School of Business and Management, Lappeenranta University of Technology, P. O. Box 20, 53851 Lappeenranta, Finland) and

Susan Mueller (Swiss Research Institute of Small Business and Entrepreneurship University of St. Gallen, Dufourstrasse 40a, 9000 St. Gallen, Switzerland) 
Accepted Author Manuscript: Electronic version of an article published as Journal of Enterprising Culture 2018 26:02, 113-153 [https://doi.org/10.1142/S021849581850005X] C [copyright World Scientific Publishing Company] [https://www.worldscientific.com/doi/abs/10.1142/S021849581850005X]

"I Want to Be Like You!": The Influence of Role Models on Entrepreneurial Intention

Katharina Fellnhofer (LUT School of Business and Management, Lappeenranta University of Technology, P. O. Box 20, 53851 Lappeenranta, Finland) and

Susan Mueller (Swiss Research Institute of Small Business and Entrepreneurship University of St. Gallen, Dufourstrasse 40a, 9000 St. Gallen, Switzerland)

Table 1

Characteristics of the sample

\begin{tabular}{|c|c|c|c|c|c|}
\hline & \multicolumn{4}{|c|}{ Nationality } & \multirow{2}{*}{ Individuals } \\
\hline & Austria & Finland & Greece & Other & \\
\hline \multicolumn{6}{|l|}{ Age } \\
\hline Up to 24 years & 76 & 62 & 61 & 15 & 214 \\
\hline Over 24 years & 16 & 7 & 18 & 11 & 52 \\
\hline \multicolumn{6}{|c|}{ Entrepreneurship Experience } \\
\hline Low experience & 69 & 53 & 55 & 7 & 184 \\
\hline High experience & 23 & 16 & 24 & 19 & 82 \\
\hline \multicolumn{6}{|l|}{ Gender } \\
\hline Male & 71 & 39 & 34 & 19 & 163 \\
\hline \multirow[t]{2}{*}{ Female } & 21 & 30 & 45 & 7 & 103 \\
\hline & 92 & 69 & 79 & 26 & 266 \\
\hline
\end{tabular}

Table 2

Measurement Instruments

Role model (5 items modified from Nauta, and Kokaly 2001), Cronbach's $\alpha=0.809$

Please indicate your level of agreement with the following statements.

(7-point scale ranging from "strongly disagree" to "strongly agree")

1. There is an entrepreneurial person I am trying to be like in my career pursuits.

2. There is an entrepreneurial person particularly inspirational to me in my career path.

3. In the career path I am pursuing, there is an entrepreneurial person I admire.

4. I have a mentor in my potential entrepreneurial career field.

5. I know of an entrepreneurial person who has a career I would like to pursue.

Entrepreneurial attitudes (5 items modified from Liñán, and Chen 2009): Cronbach's $\alpha=0.880$

Please indicate your level of agreement with the following statements.

(7-point scale ranging from "strongly disagree" to "strongly agree")

1. Being an entrepreneur implies more advantages than disadvantages to me.

2. A career as entrepreneur is attractive to me.

3. If I had the opportunity and resources, I'd like to start a firm.

4. Being an entrepreneur would entail great satisfaction for me.

5. Among various options, I would rather be an entrepreneur.

Subjective norms (4 items modified from Liñán and Chen, 2009; Kautonen et al., 2013):

Cronbach's $\alpha=0.737$ 
Accepted Author Manuscript: Electronic version of an article published as Journal of Enterprising Culture 2018 26:02, 113-153 [https://doi.org/10.1142/S021849581850005X] C) [copyright World Scientific Publishing Company] [https://www.worldscientific.com/doi/abs/10.1142/S021849581850005X]

"I Want to Be Like You!": The Influence of Role Models on Entrepreneurial Intention

Katharina Fellnhofer (LUT School of Business and Management, Lappeenranta University of Technology, P. O. Box 20, 53851 Lappeenranta, Finland) and

Susan Mueller (Swiss Research Institute of Small Business and Entrepreneurship University of St. Gallen, Dufourstrasse 40a, 9000 St. Gallen, Switzerland)

If you decided to create a firm in the next 12 months, who in your close environment would approve of that decision? (7-point scale ranging from "strongly disagree" to "strongly agree")

1. Parents

2. Siblings

3. Friends

4. Someone else who is important to me and/or someone I do not know personally

Perceived behavioral control (6 items modified from Liñán and Chen, 2009): Cronbach's $\alpha=0.874$

To what extent do you agree with the following statements regarding your entrepreneurial capacity? (7-point scale ranging from "strongly disagree" to "strongly agree")

1. To start a firm and keep it working would be easy for me.

2. I am prepared to start a viable firm.

3. I can control the creation process of a new firm.

4. I know the necessary practical details to start a firm.

5. I know how to develop an entrepreneurial project.

6. If I tried to start a firm, I would have a high probability of succeeding.

Entrepreneurial self-efficacy (10 items modified from Chen, Gully, and Eden 2001; Kickul, Gundry, Barbosa, and Whitcanack 2009): Cronbach's $\alpha=0.859$

I feel very competent and confident that I could ...

(7-point scale ranging from "strongly disagree" to "strongly agree")

1. conceive a unique idea for a business

2. identify market opportunities for a new business

3. plan a new business

4. write a formal business plan

5. raise money to start a business

6. convince others to invest in my business

7. convince a bank to lend me money to start a business

8. convince others to work for me in my new business

9. manage a small business

10. grow a successful business

Perceived desirability (3 items modified from Peterman, and Kennedy 2003): Cronbach's $\alpha=0.827$

Please indicate your level of agreement with the following statements.

(7-point scale ranging from "strongly disagree" to "strongly agree")

1. I would love to start my own business.

2. I would be very tense to start my own business.

3. I would be very enthusiastic to start my own business.

Perceived feasibility ( 5 items modified from Peterman, and Kennedy 2003): Cronbach's $\alpha=0.674$ 
Accepted Author Manuscript: Electronic version of an article published as Journal of Enterprising Culture 2018 26:02, 113-153 [https://doi.org/10.1142/S021849581850005X] C) [copyright World Scientific Publishing Company] [https://www.worldscientific.com/doi/abs/10.1142/S021849581850005X]

"I Want to Be Like You!": The Influence of Role Models on Entrepreneurial Intention

Katharina Fellnhofer (LUT School of Business and Management, Lappeenranta University of Technology, P. O. Box 20, 53851 Lappeenranta, Finland) and

Susan Mueller (Swiss Research Institute of Small Business and Entrepreneurship University of St. Gallen, Dufourstrasse 40a, 9000 St. Gallen, Switzerland)

Please indicate your level of agreement with the following statements!

(7-point scale ranging from "strongly disagree" to "strongly agree")

1. It will be easy to start my own business.

2. I will be successful when I have my own business.

3. I won't be overworked when I have my own business.

4. I know enough how to start a business.

5. I am sure about myself.

Entrepreneurial intention (6 items modified from Liñán, and Chen 2009): Cronbach's $\alpha=0.922$

Please indicate your level of agreement with the following statements!

1. I am ready to do anything to be an entrepreneur.

2. My professional goal is to become an entrepreneur.

3. I will make every effort to start and run my own firm.

4. I am determined to create a firm in the future.

5. I have very seriously thought of starting a firm.

6. I have the firm intention to start a firm some day.

\section{Table 3}

Construct means, standard deviations, and correlations among variables.

\begin{tabular}{|c|c|c|c|c|c|c|c|c|c|c|c|c|c|c|c|}
\hline & & Mean & $S D$ & 1 & 2 & 3 & 4 & 5 & 6 & 7 & 8 & 9 & 10 & 11 & 12 \\
\hline 1 & Role Model & 4.09 & 1.21 & 1 & & & & & & & & & & & \\
\hline 2 & $\begin{array}{l}\text { Subjective } \\
\text { Norms }\end{array}$ & 5.03 & 1.18 & $.277^{* *}$ & 1 & & & & & & & & & & \\
\hline 3 & $\begin{array}{l}\text { Entrepreneurial } \\
\text { Attitudes }\end{array}$ & 4.67 & 1.21 & $.401^{* *}$ & $.425^{* *}$ & 1 & & & & & & & & & \\
\hline 4 & Self-efficacy & 4.52 & 0.94 & $.276^{* *}$ & $.304^{* *}$ & $.355^{* *}$ & 1 & & & & & & & & \\
\hline 5 & $\begin{array}{l}\text { Perceived Behav- } \\
\text { ioral Control }\end{array}$ & 3.72 & 1.13 & $205^{* *}$ & $.148^{*}$ & $.299^{* *}$ & $.548^{* *}$ & 1 & & & & & & & \\
\hline 6 & $\begin{array}{l}\text { Perceived Desira- } \\
\text { bility }\end{array}$ & 4.58 & 1.37 & $.326^{* *}$ & $.354^{* *}$ & $.662^{* *}$ & $.416^{* *}$ & $.300^{* *}$ & 1 & & & & & & \\
\hline 7 & $\begin{array}{l}\text { Perceived Feasi- } \\
\text { bility }\end{array}$ & 3.58 & 0.97 & $.176^{* *}$ & $.213^{* *}$ & $.287^{* *}$ & $.544^{* *}$ & $.688^{* *}$ & $.349^{* *}$ & 1 & & & & & \\
\hline 8 & $\begin{array}{l}\text { Entrepreneurial } \\
\text { Intention }\end{array}$ & 3.81 & 1.42 & $.311^{* *}$ & $.248^{* *}$ & $.620^{* *}$ & $.416^{* *}$ & $.536^{* *}$ & $.651^{* *}$ & $.426^{* *}$ & 1 & & & & \\
\hline 9 & Gender & 0.39 & 0.49 & .040 & .080 & -.021 & $-.121^{*}$ & $-.189^{* *}$ & -.094 & $-.197^{* *}$ & -.091 & 1 & & & \\
\hline 10 & Age & 0.20 & 0.40 & .004 & .071 & -.003 & .015 & $.230^{* *}$ & .050 & $.159^{* *}$ & .095 & -.119 & 1 & & \\
\hline 11 & Nation & 2.15 & 1.01 & .093 & .048 & $.125^{*}$ & $.141^{*}$ & .006 & .088 & -.060 & .022 & $.176^{* *}$ & $.154^{*}$ & 1 & \\
\hline 12 & $\begin{array}{l}\text { Entrepreneurship } \\
\text { Experience }\end{array}$ & 0.31 & 0.46 & $.248^{* *}$ & .093 & $.241^{* *}$ & $.230^{* *}$ & $.318^{* *}$ & $.197^{* *}$ & $.197^{* *}$ & $.294^{* *}$ & -.079 & $.328^{* *}$ & $.218^{* *}$ & 1 \\
\hline
\end{tabular}

Note: $\mathrm{n}=266$; Pearson correlation (bivariate); standard deviation (SD)

**. Correlation is significant at the 0.01 level (2-tailed). *. Correlation is significant at the 0.05 level (2-tailed).

Table 4

Overview of Relationships for the Theory of Planned Behavior 
Accepted Author Manuscript: Electronic version of an article published as Journal of Enterprising Culture 2018 26:02, 113-153 [https://doi.org/10.1142/S021849581850005X] C) [copyright World Scientific Publishing Company] [https://www.worldscientific.com/doi/abs/10.1142/S021849581850005X]

"I Want to Be Like You!": The Influence of Role Models on Entrepreneurial Intention

Katharina Fellnhofer (LUT School of Business and Management, Lappeenranta University of Technology, P. O. Box 20, 53851 Lappeenranta, Finland) and

Susan Mueller (Swiss Research Institute of Small Business and Entrepreneurship University of St. Gallen, Dufourstrasse 40a, 9000 St. Gallen, Switzerland)

$\begin{array}{lcc}\text { Relationship } & \begin{array}{c}\text { Standardized Re- } \\ \text { gression Weights } \\ \text { (SRW) }\end{array} & \begin{array}{c}\text { Standard } \\ \text { Error } \\ (S E)\end{array}\end{array} \mathrm{R}^{2}$

Table 5

Overview of Relationships for the Entrepreneurial Event Model

\begin{tabular}{cccc} 
Relationship & $\begin{array}{c}\text { Standardized Re- } \\
\text { gression Weights } \\
\text { (SRW) }\end{array}$ & $\begin{array}{c}\text { Standard } \\
\text { Error } \\
(S E)\end{array}$ & $\mathrm{R}^{2}$ \\
\hline Perceived Desirability - Entrepreneurial Intention & $.652^{* * *}$ & .056 & .619 \\
Perceived Feasibility - Entrepreneurial Intention & $.233^{* * *}$ & .087 & $.065 ;$ Stan
\end{tabular}

Note: $\chi^{2}=315.502 ; \chi^{2} / \mathrm{df}=2.13 ; \mathrm{GFI}=0.896 ; \mathrm{CFI}=0.924 ; \mathrm{TLI}=0.902 ; \mathrm{IFI}=0.925 ; \mathrm{RMSEA}=0.065 ;$ Standardized regression weights (SRW) are marked as follows $\dagger p<.10 ; * p<.05 ; * * p<.01 ; * * *<.001$. Age (coded " 0 " for below 24 years and " 1 " for above 24 years); gender (coded " 1 " for female, and " 0 " for male), nation (" 1 " for Austria, " 2 " for Finland, "3" for Greece, " 4 " for others) had paths to independent and dependent variables. The significant standardized coefficients for the control variable are as follows: gender - perceived desirability $=-0.340 \dagger$; gender perceived feasibility $=-0.295 *$; experience — perceived desirability $=0.748 * * *$; age — perceived feasibility $=0.325 \dagger$; experience — perceived feasibility $=0.446^{* *}$; Greece — perceived desirability $=0.491^{*}$; Greece — perceived feasibility $=-0.453^{* *}$; experience - entrepreneurial intention $=0.255 \dagger$; Finland - entrepreneurial intention $=-0.28^{*}$.

Table 6a

Overview of Relationships for the Theory of Planned Behavior including Role Model

\begin{tabular}{lccc} 
Relationship & $\begin{array}{c}\text { Standardized } \\
\text { Regression } \\
\text { Weights (SRW) }\end{array}$ & $\begin{array}{c}\text { Standard } \\
\text { Error } \\
(S E)\end{array}$ & $\mathrm{R}^{2}$ \\
\hline Role Model - Entrepreneurial Attitudes & $.414^{* * *}$ & .060 & .254 \\
Role Model - Subjective Norms & $.331^{* * *}$ & .077 & .186 \\
Role Model - Self-efficacy & $.287^{* * *}$ & .047 & .228
\end{tabular}


Accepted Author Manuscript: Electronic version of an article published as Journal of Enterprising Culture 2018 26:02, 113-153 [https://doi.org/10.1142/S021849581850005X] C [copyright World Scientific Publishing Company] [https://www.worldscientific.com/doi/abs/10.1142/S021849581850005X]

"I Want to Be Like You!": The Influence of Role Models on Entrepreneurial Intention

Katharina Fellnhofer (LUT School of Business and Management, Lappeenranta University of Technology, P. O. Box 20, 53851 Lappeenranta, Finland) and

Susan Mueller (Swiss Research Institute of Small Business and Entrepreneurship University of St. Gallen, Dufourstrasse 40a, 9000 St. Gallen, Switzerland)

\begin{tabular}{lccc} 
Role Model - Perceived Behavioral Control & $.175^{* *}$ & .054 & .184 \\
\hline Entrepreneurial Attitudes - Entrepreneurial Intention & $.531^{* * *}$ & .095 & \\
Subjective Norms - Entrepreneurial Intention & -.020 & .073 & .615 \\
Self-efficacy - Entrepreneurial Intention & .043 & .148 & \\
Perceived Behavioral Control - Entrepreneurial Intention & $.399^{* * *}$ & .117 & \\
\hline
\end{tabular}

Note: $\chi 2=1042,018 ; \chi^{2} / \mathrm{df}=1.82 ; \mathrm{GFI}=0.813 ; \mathrm{CFI}=0.902 ; \mathrm{TLI}=0.889 ; \mathrm{IFI}=0.904 ; \mathrm{RMSEA}=0.051$. Standardized regression weights (SRW) are marked as follows $\dagger p<.10 ; * p<.05 ; * * p<.01$; *** $p<.001$. Age (coded " 0 " for below 24 years and " 1 " for above 24 years); gender (coded " 1 " for female, and " 0 " for male), nation (" 1 " for Austria, " 2 " for Finland, "3" for Greece, "4" for others) had paths to independent and dependent variables. The significant standardized coefficients for the control variable are as follows: entrepreneurial experience — role model $=0.317^{* * *}$; age — role model $=-0.113 \uparrow$; experience - entrepreneurial attitudes $=0.155^{*}$; entrepreneurial experience - perceived behavioral control $=0.226^{* *}$; entrepreneurial experience - self-efficacy $=0.156^{*}$; age - subjective norms $=0.125 \dagger$; age - perceived behavioral control $=0.157 *$; Finland - subjective norms $=0.222 * *$; Finland - self-efficacy $=$ $0.247^{* *}$; Greece - self-efficacy $=0.195 *$; other nations - self-efficacy $=0.132 \uparrow$; gender - self-efficacy $=-0.161 *$; gender - self-efficacy $=-0.189 * *$; Finland - entrepreneurial intention $=-0.126^{*}$.

\section{Table 6b}

Overview of Relationships for the Entrepreneurial Event Model including Role Model

\begin{tabular}{lccc} 
Relationship & $\begin{array}{c}\text { Standardized Re- } \\
\text { gression Weights } \\
\text { (SRW) }\end{array}$ & $\begin{array}{c}\text { Standard } \\
\text { Error }(S E)\end{array}$ & $\mathrm{R}^{2}$ \\
\hline Role Model - Perceived Desirability & $.342^{* * *}$ & .082 & .175 \\
Role Model - Perceived Feasibility & $.149 \dagger$ & .060 & .188 \\
\hline Perceived Desirability - Entrepreneurial Intention & $.680^{* * *}$ & .055 & \multirow{2}{*}{.598} \\
Perceived Feasibility - Entrepreneurial Intention & $.270^{* * *}$ & .083 & \multirow{2}{*}{. } \\
\hline
\end{tabular}

Note: $\chi 2=315.502 ; \chi 2 / \mathrm{df}=2.13 ; \mathrm{GFI}=0.896 ; \mathrm{CFI}=0.924 ; \mathrm{TLI}=0.902 ; \mathrm{IFI}=0.925 ; \mathrm{RMSEA}=0.065 ;$ Standardized regression weights (SRW) are marked as follows $\dagger p<.10 ; * p<.05 ; * * p<.01$; *** $p<.001$. Age (coded " 0 " for below 24 years and " 1 " for above 24 years); gender (coded " 1 " for female, and " 0 " for male), nation (" 1 " for Austria, " 2 " for Finland, "3" for Greece, "4" for others) had paths to independent and dependent variables. The significant standardized coefficients for the control variable are as follows: age — role model $=-0.113 \uparrow$; Finland - entrepreneurial intention $=-0.106 \dagger$; entrepreneurial experience - entrepreneurial intention $=0.090 \dagger$; entrepreneurial experience entrepreneurial desirability $=0.112 \uparrow$; Greece — perceived feasibility $=-0.221 * *$; entrepreneurial experience — role model $=0.316^{* * *}$; Greece - entrepreneurial desirability $=0.149^{*}$; gender - entrepreneurial desirability $=-0.122 *$; age - perceived feasibility $=0.156^{*}$; entrepreneurial experience - perceived feasibility $=0.171^{*}$; gender — perceived feasibility $=-0.161^{*}$.

Table 6c

Results of Structural Equation Model (TPB and EEM) including Role Model

Relationship
Standardized Regression Weights (SRW)
Role Model - Theory of Planned Behavior

Role Model - Entrepreneurial Attitudes

Role Model - Subjective Norms

$.417 * * *$

$.347 * * *$
Standard

Error $(S E) \quad \mathrm{R}^{2}$ 
Accepted Author Manuscript: Electronic version of an article published as Journal of Enterprising Culture 2018 26:02, 113-153 [https://doi.org/10.1142/S021849581850005X] C) [copyright World Scientific Publishing Company] [https://www.worldscientific.com/doi/abs/10.1142/S021849581850005X]

"I Want to Be Like You!": The Influence of Role Models on Entrepreneurial Intention

Katharina Fellnhofer (LUT School of Business and Management, Lappeenranta University of Technology, P. O. Box 20, 53851 Lappeenranta, Finland) and

Susan Mueller (Swiss Research Institute of Small Business and Entrepreneurship University of St. Gallen, Dufourstrasse 40a, 9000 St. Gallen, Switzerland)

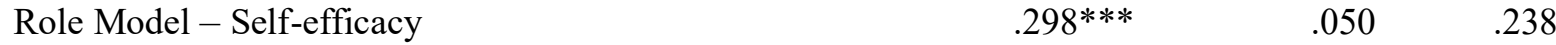

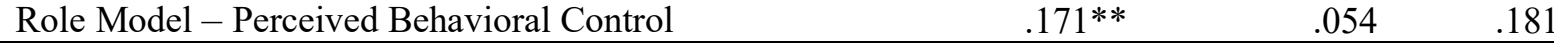

Entrepreneurial Event Model

Entrepreneurial Attitudes - Perceived Desirability

Subjective Norms - Perceived Desirability

Self-efficacy - Perceived Desirability

Perceived Behavioral Control - Perceived Desirability

Self-efficacy - Perceived Feasibility

Perceived Behavioral Control - Perceived Feasibility

Perceived Desirability - Entrepreneurial Intention

Perceived Feasibility - Entrepreneurial Intention

$.681^{* * *} \quad .118$

-.034 (n.s.) $\quad .080$

$.294 * * 178$

$.030($ n.s. $) \quad .114$

$.270 * * \quad .096$

$.733 * * * \quad .103$

$.612 * * * \quad .055$

$.325^{* * *} \quad .101$

$101 \quad .670$

Note: $\chi^{2}=1804,799 ; \chi^{2} / \mathrm{df}=1.65 ; \mathrm{GFI}=0.792 ; \mathrm{CFI}=0.893 ; \mathrm{TLI}=0.881 ; \mathrm{IFI}=0.895 ; \mathrm{RMSEA}=0.050$. Standardized regression weights (SRW) are marked as follows $\dagger p<.10 ; * p<.05 ; * * p<.01 ; * * * p<.001$. Entrepreneurial experience- perceived behavioral control $=0.224^{* *}$; gender - self-efficacy $=-0.175^{* *}$; Finland - subjective norms $=$ $0.202^{* *}$; age - Perceived Feasibility $=-0.191^{* *}$; age - perceived behavioral control $=0.156^{*}$; entrepreneurial experience - self-efficacy $=0.155^{*}$; entrepreneurial experience - entrepreneurial attitudes $=0.155^{*}$; gender - perceived behavioral control $=-0.157^{*} ;$ age - self-efficacy $=0.191 *$; other nation - self-efficacy $=0.132 *$; Finland- Perceived Feasibility $=-0.109^{*}$; Finland - Perceived Desirability $=-0.111 \dagger ;$ age - role model $=-0.113 \dagger ;$ age - subjective norms $=0.118 \dagger ;$ entrepreneurial experience - role model $=0.316^{* * *}$; Finland - self-efficacy $=0.263^{* * *}$.

\section{Table 7}

Summary of goodness-of-fit indices for the model.

\begin{tabular}{lcccccccc}
\multicolumn{1}{c}{ Fit indices } & $\chi \mathbf{2}$ & $\mathbf{p}-\mathbf{v a l u e}$ & $\chi^{\mathbf{2}} \mathbf{d f}$ & GFI & CFI & TLI & IFI & RMSEA \\
\hline & & & & & & & & \\
Model TPB & 1043.892 & 0.00 & 1.79 & .826 & .905 & .891 & .906 & .055 \\
Model EEM & 315.502 & 0.00 & 2.13 & .896 & .924 & .902 & .925 & .065 \\
Model RM-TPB & 1042.018 & 0.00 & 1.82 & .813 & .902 & .889 & .904 & .051 \\
Model RM-EEM & 475.285 & 0.00 & 1.93 & .878 & .916 & .898 & .918 & .059 \\
Model RM-TPB-EEM & 1804.799 & 0.00 & 1.65 & .792 & .893 & .881 & .895 & .050 \\
Recommended values & & $<0.05$ & $<5$ & $>0.80$ & $>0.90$ & $>0.90$ & $>0.90$ & $<0.07$ \\
\hline
\end{tabular}

Notes: Theory of Planned Behavior (TPB), Entrepreneurial Event Model (EEM), Role Model (RM), Goodness-of-Fit Index (GFI), Comparative Fit Index (CFI), Tucker Lewis Index (TLI), Incremental Fit Index (IFI), Root Mean Square Residual (RMSEA).

\section{Table 8}

Overview of the hypotheses and results

\section{Hypothesis}

Result

\#1: Attitudes, subjective norms, entrepreneurial self-efficacy, and perceived behav- Partially supported ioral control are positively related to entrepreneurial intention.

\#2: Perceived desirability and perceived feasibility are positively related to EI. $\quad$ Supported

\#3: Entrepreneurial role models are positively related to attitudes, subjective Supported norms, entrepreneurial self-efficacy, and perceived behavioral control. 
Accepted Author Manuscript: Electronic version of an article published as Journal of Enterprising Culture 2018 26:02, 113-153 [https://doi.org/10.1142/S021849581850005X] C) [copyright World Scientific Publishing Company] [https://www.worldscientific.com/doi/abs/10.1142/S021849581850005X]

"I Want to Be Like You!": The Influence of Role Models on Entrepreneurial Intention

Katharina Fellnhofer (LUT School of Business and Management, Lappeenranta University of Technology, P. O. Box 20, 53851 Lappeenranta,

Finland) and

Susan Mueller (Swiss Research Institute of Small Business and Entrepreneurship University of St. Gallen, Dufourstrasse 40a, 9000 St. Gallen, Switzerland)

\begin{tabular}{ll}
\hline \#4: Entrepreneurial role models are positively related to desirability and feasibility & Supported \\
\hline \#5a: Entrepreneurial role models are positively related to attitudes, subjective & Supported \\
norms, entrepreneurial self-efficacy, and perceived behavioral control. & \\
\hline \#5b: Attitudes, subjective norms, entrepreneurial self-efficacy, and perceived be- & Supported \\
havioral control are positively related to perceived desirability. & \\
\hline \#5c: Entrepreneurial self-efficacy and perceived behavioral control are positively & Supported \\
related to perceived feasibility. & \\
\hline
\end{tabular}


Accepted Author Manuscript: Electronic version of an article published as Journal of Enterprising Culture 2018 26:02, 113-153 [https://doi.org/10.1142/S021849581850005X] C [copyright World Scientific Publishing Company] [https://www.worldscientific.com/doi/abs/10.1142/S021849581850005X]

"I Want to Be Like You!": The Influence of Role Models on Entrepreneurial Intention

Katharina Fellnhofer (LUT School of Business and Management, Lappeenranta University of Technology, P. O. Box 20, 53851 Lappeenranta, Finland) and

Susan Mueller (Swiss Research Institute of Small Business and Entrepreneurship University of St. Gallen, Dufourstrasse 40a, 9000 St. Gallen, Switzerland)

\section{Table 9}

Confirmatory factor analysis.

\begin{tabular}{|c|c|c|c|c|c|c|c|c|c|c|}
\hline 它苞 & Items & Mean & $\mathrm{SD}$ & $\begin{array}{l}\text { Standardized } \\
\text { factor load- } \\
\text { ings }^{\text {a }}\end{array}$ & $\begin{array}{l}\text { Composite } \\
\text { reliability } \\
\geq 0.6^{\mathrm{b}}\end{array}$ & $\begin{array}{c}\text { Cronbach's } \\
\alpha \geq 0.7^{\mathrm{c}}\end{array}$ & $\begin{array}{l}\text { AVE } \\
\geq 0.5^{\mathrm{d}}\end{array}$ & $\begin{array}{c}\text { Kaiser-Meyer-Olkin } \\
\text { Measure of Sam- } \\
\text { pling Adequacy }\end{array}$ & $\begin{array}{c}\text { Determi- } \\
\text { nant }^{\mathrm{f}}\end{array}$ & $\begin{array}{c}\text { Bartlett's } \\
\text { Test of } \\
\text { Sphericity }\end{array}$ \\
\hline \multirow{5}{*}{$\begin{array}{l}\overline{0} \\
\sum_{0}^{0} \\
\frac{0}{0} \\
\simeq 1\end{array}$} & RM_1 & 4.27 & 1.58 & 0.801 & \multirow{5}{*}{0.816} & \multirow{5}{*}{0.809} & \multirow{5}{*}{0.484} & \multirow{5}{*}{0.788} & \multirow{5}{*}{0.165} & \multirow{5}{*}{472.53} \\
\hline & RM_2 & 4.25 & 1.61 & 0.868 & & & & & & \\
\hline & RM_3 & 4.38 & 1.55 & 0.713 & & & & & & \\
\hline & RM_4 & 3.29 & 1.67 & 0.427 & & & & & & \\
\hline & RM_5 & 4.27 & 1.64 & 0.577 & & & & & & \\
\hline \multirow{5}{*}{ 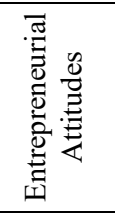 } & EA_1 & 4.54 & 1.49 & 0.675 & \multirow{5}{*}{0.884} & \multirow{5}{*}{0.88} & \multirow{5}{*}{0.605} & \multirow{5}{*}{0.848} & \multirow{5}{*}{0.066} & \multirow{5}{*}{713.53} \\
\hline & EA_2 & 4.75 & 1.49 & 0.87 & & & & & & \\
\hline & EA_3 & 5.06 & 1.43 & 0.679 & & & & & & \\
\hline & EA_4 & 4.75 & 1.45 & 0.836 & & & & & & \\
\hline & EA_5 & 4.25 & 1.51 & 0.809 & & & & & & \\
\hline \multirow{4}{*}{ 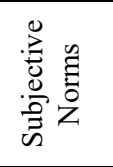 } & SN_1 & 4.98 & 1.77 & 0.692 & \multirow{4}{*}{0.749} & \multirow{4}{*}{0.737} & \multirow{4}{*}{0.432} & \multirow{4}{*}{0.716} & \multirow{4}{*}{0.386} & \multirow{4}{*}{250.38} \\
\hline & SN_2 & 4.85 & 1.63 & 0.68 & & & & & & \\
\hline & SN_3 & 5.29 & 1.37 & 0.728 & & & & & & \\
\hline & $\mathrm{SN} \_4$ & 5.00 & 1.53 & 0.506 & & & & & & \\
\hline \multirow{10}{*}{ 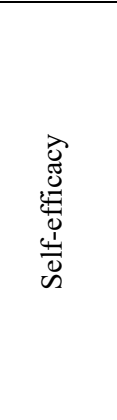 } & ESE_1 & 4.50 & 1.42 & 0.569 & & & & & & \\
\hline & ESE_2 & 4.53 & 1.29 & 0.711 & & & & & & \\
\hline & ESE_3 & 4.57 & 1.38 & 0.71 & & & & & & \\
\hline & ESE_4 & 4.23 & 1.52 & 0.651 & & & & & & \\
\hline & ESE_5 & 4.05 & 1.49 & 0.546 & & & 0344 & 0831 & & \\
\hline & ESE_6 & 4.35 & 1.51 & 0.542 & 0.831 & & 0.344 & 0.831 & 0.016 & 1082.13 \\
\hline & ESE_7 & 4.24 & 1.58 & 0.441 & & & & & & \\
\hline & ESE_8 & 4.85 & 1.33 & 0.51 & & & & & & \\
\hline & ESE_9 & 5.12 & 1.30 & 0.51 & & & & & & \\
\hline & ESE_10 & 4.80 & 1.28 & 0.615 & & & & & & \\
\hline & $\mathrm{PBC}_{-} 1$ & 3.61 & 1.43 & 0.672 & & & & & & \\
\hline 胥 $\overline{0}$ & $\mathrm{PBC}_{-} 2$ & 3.54 & 1.49 & 0.822 & & & & & & \\
\hline ص & $\mathrm{PBC}_{-} 3$ & 4.09 & 1.37 & 0.755 & 0868 & 0874 & 0788 & 0849 & 0048 & 79631 \\
\hline$\sum_{0}^{0} \frac{0}{\pi}$ & $\mathrm{PBC}_{-} 4$ & 3.46 & 1.57 & 0.78 & 0.808 & $0.8 / 4$ & 0.188 & 0.849 & 0.048 & \\
\hline 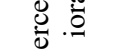 & $\mathrm{PBC} \_5$ & 3.45 & 1.48 & 0.69 & & & & & & \\
\hline & $\mathrm{PBC} \_6$ & 4.16 & 1.31 & 0.609 & & & & & & \\
\hline $\mathbb{D}_{j}>$ & PD_1 & 4.51 & 1.72 & 0.878 & & & & & & \\
\hline 焉 & PD_2 & 4.49 & 1.47 & 0.623 & 0.819 & 0.827 & 0.607 & 0.697 & 0.308 & 309.914 \\
\hline D & PD_3 & 4.73 & 1.58 & 0.813 & & & & & & \\
\hline & PF_1 & 2.56 & 1.40 & 0.597 & & & & & & \\
\hline & PF_2 & 4.39 & 1.23 & 0.474 & & & & & & \\
\hline$\stackrel{D}{D}$ & PF_3 & 3.11 & 1.51 & 0.345 & 0.659 & 0.674 & 0.364 & 0.66 & 0.444 & 213.01 \\
\hline ] & PF_4 & 2.98 & 1.65 & 0.737 & & & & & & \\
\hline$\stackrel{5}{0}$ & PF_5 & 4.85 & 1.53 & 0.463 & & & & & & \\
\hline$\dot{d} \stackrel{1}{=}$ & I_1 & 3.21 & 1.64 & 0.737 & & & & & & \\
\hline 党 & I_ 2 & 3.68 & 1.70 & 0.776 & 0919 & 0922 & 0656 & 0886 & 001 & 120393 \\
\hline$\underset{\Xi}{\Xi} \stackrel{\Xi}{\Xi}$ & I_3 & 3.71 & 1.60 & 0.875 & 0.919 & 0.922 & 0.050 & 0.880 & & \\
\hline II $=$ & I_4 & 4.06 & 1.65 & 0.87 & & & & & & \\
\hline
\end{tabular}


Accepted Author Manuscript: Electronic version of an article published as Journal of Enterprising Culture 2018 26:02, 113-153 [https://doi.org/10.1142/S021849581850005X] C) [copyright World Scientific Publishing Company] [https://www.worldscientific.com/doi/abs/10.1142/S021849581850005X]

"I Want to Be Like You!": The Influence of Role Models on Entrepreneurial Intention

Katharina Fellnhofer (LUT School of Business and Management, Lappeenranta University of Technology, P. O. Box 20, 53851 Lappeenranta, Finland) and

Susan Mueller (Swiss Research Institute of Small Business and Entrepreneurship University of St. Gallen, Dufourstrasse 40a, 9000 St. Gallen, Switzerland)

$\begin{array}{llll}\text { I_5 } & 4.00 & 1.76 & 0.817 \\ \text { I } 6 & 4.22 & 1.69 & 0.776\end{array}$

${ }^{\mathrm{a}}$ All factor loadings are significant $(\mathrm{p}<0.001) .{ }^{\mathrm{b}}$ Bagozzi (1988); Raykov (1997). ${ }^{\mathrm{c}}$ All Cronbach's alpha are greater than 0.6 (Nunnally 1978 ; Hair, Anderson, Tatham, and Black 1995). ${ }^{\mathrm{d}}$ Fornell and Larcker (1981). ${ }^{\mathrm{e}}$ All Kaiser-Meyer-Olkin Measures of Sampling Adequacy are more than 0.5 (Kaiser 1974). ${ }^{\mathrm{f}}$ All determinants of the constructs' correlation matrix are greater than the necessary value of $0.00001 .{ }^{\mathrm{g}}$ All significant values conclude that there are suitable correlations in the data set (Bartlett 